Illinois State University

ISU ReD: Research and eData

Theses and Dissertations

$5-20-2014$

\title{
Latino Emergent Bilingual Students' Experiences with the Middle School Transition
}

Kerry Pecho

Illinois State University, kpecho@gmail.com

Follow this and additional works at: https://ir.library.illinoisstate.edu/etd

Part of the Bilingual, Multilingual, and Multicultural Education Commons, Elementary and Middle and Secondary Education Administration Commons, Junior High, Intermediate, Middle School Education and Teaching Commons, and the Psychology Commons

\section{Recommended Citation}

Pecho, Kerry, "Latino Emergent Bilingual Students' Experiences with the Middle School Transition" (2014). Theses and Dissertations. 233.

https://ir.library.illinoisstate.edu/etd/233

This Thesis is brought to you for free and open access by ISU ReD: Research and eData. It has been accepted for inclusion in Theses and Dissertations by an authorized administrator of ISU ReD: Research and eData. For more information, please contact ISUReD@ilstu.edu. 


\title{
LATINO EMERGENT BILINGUAL STUDENTS’ EXPERIENCES WITH THE MIDDLE SCHOOL TRANSITION
}

\author{
Kerry Pecho
}

95 Pages

December 2014

The purpose of this study was to learn how native Spanish-speaking students who attended a bilingual elementary school program anticipated and experienced the transition to middle school. Research shows that language and support services for bilingual students are significantly reduced or modified upon entry into middle school. Given this change in support, research suggests that bilingual students may experience unique challenges compared to their English-only peers. Although there is a fair amount of literature on the middle school transition in general, as well as quantitative research about the declines in the academic performance of Latino students transitioning to middle and high school, there is a need for research that seeks to understand the middle school transition from the student perspective, specifically that of Latino emergent bilingual students.

To begin exploring this perspective, two focus groups were conducted with Latino emergent bilingual students in sixth, seventh, and eighth grade, all of whom attended a Spanish-English bilingual elementary school program. One group included three sixth grade students, and the other group included three seventh-grade and two eighth-grade students. Each discussion was audiotaped and later transcribed verbatim. Two researchers 
completed each of the three stages of data coding to reach concordance on codes, categories, and overarching themes. Overall, participants described positive transition experiences, including strong relationships with their teachers, satisfying new friendships, enjoyable junior-high activities, and informational and emotional support. Participants' responses also suggested that the transition to junior high school created a dilemma for them. Specifically, their increasing English fluency came at the expense of their Spanish language. The results of this study are intended to alert researchers, practitioners, and family members about emergent bilingual students' resiliency factors, unique concerns, and beneficial supports. They may also be used to inform elementary- to middle-school transition programming. 


\title{
LATINO EMERGENT BILINGUAL STUDENTS' EXPERIENCES WITH THE MIDDLE SCHOOL TRANSITION
}

KERRY PECHO

\author{
A Thesis Submitted in Partial \\ Fulfillment of the Requirements \\ for the Degree of \\ MASTER OF SCIENCE \\ Department of Psychology \\ ILLINOIS STATE UNIVERSITY
}




\section{LATINO EMERGENT BILINGUAL STUDENTS' EXPERIENCES}

WITH THE MIDDLE SCHOOL TRANSITION

KERRY PECHO

COMMITTEE MEMBERS:

Adena Meyers, Chair

Steve Landau

Rocío Rivadeneyra 


\section{ACKNOWLEDGMENTS}

I would like to thank my committee chair, Dr. Adena Meyers, for reintroducing me to qualitative research and challenging me to dig deeper into my findings and improve my writing. I would also like to thank Dr. Steve Landau for helping me craft this project, for providing invaluable feedback, and for his flexibility. Additionally, I greatly appreciate Dr. Rocio Rivadeneyra for exposing me to new literature, emphasizing clarity, and highlighting an asset-based approach. My committee members were very generous with their time and extremely helpful in their guidance.

I would also like to thank Verencie D'Santiago and Carolina Elizondo for their assistance with translating and back-translating the permission documents. Additionally, I would like to express my appreciation for Jennifer Mays for her assistance with coding and for Daisy Bueno and Karina Diaz, who helped facilitate data collection. I owe Ms. Daisy a trip to the snack bar.

Finally, I would like to extend my sincere thanks to the local community center through which I recruited my participants and collected my data. The director was extremely helpful, the families were generous with their time, and the students were friendly and open to sharing their experiences. 


\section{CONTENTS}

Page

ACKNOWLEDGMENTS

CONTENTS

TABLES

CHAPTER

iv
I. THE PROBLEM AND ITS BACKGROUND 1

II. REVIEW OF RELATED LITERATURE 5

Demographics $\quad 5$

National Hispanic Demographics 5

Hispanic ELL Demographics $\quad 6$

Academic Achievement of Immigrant and Non-immigrant

Hispanic Students

Influences on Immigrant and Non-immigrant

Hispanic Student Outcomes

Perceived Discrimination

Acculturation

Generational Status

English Language Acquisition

Models of Bilingual Education

School Transition

19

Middle School Transition

Academic Outcomes

Social-Emotional and Behavioral Outcomes

Latino Students

27

ELL Students

1

5

5

5

6


Transition Supports $\quad 30$

III. $\quad$ RESEARCH DESIGN 34

Qualitative Research as Methodology 34

Participants $\quad 36$

Setting $\quad 40$

Data Collection $\quad 40$

Data Analysis $\quad 42$

Dependability 43

IV. ANALYSIS OF DATA 45

Participant Background Information $\quad 46$

Elementary School $\quad 48$

Program Structure $\quad 48$

Connection with School 49

Predominantly Latino Peer Group 51

Excitement and Uncertainty $\quad 52$

Family Support $\quad 52$

Transition Programming 53

Junior High School 54

Classroom Structure $\quad 54$

Change and Adaptation $\quad 55$

New Peer Groups and Implications for Friendships $\quad 56$

Learning and Losing Language $\quad 58$

Family Support $\quad 59$

$\begin{array}{ll}\text { School Support } & 60\end{array}$

$\begin{array}{lll}\text { V. DISCUSSION } & 63\end{array}$

Interpretations $\quad 64$

Limitations and Future Directions $\quad 67$

$\begin{array}{ll}\text { REFERENCES } & 74\end{array}$

APPENDIX A: Focus Group A Session Outline $\quad 81$

APPENDIX B: $\quad$ Focus Group B Session Outline $\quad 85$

$\begin{array}{ll}\text { APPENDIX C: } & \text { Codes and Corresponding Categories Identified } \\ & \text { During Open Coding and Axial Coding }\end{array}$ 


\section{TABLES}

Table $\quad$ Page

1. Summary of Sixth-Grade Focus Group Participants 37

2. Summary of Seventh- and Eighth-Grade Focus Group Participants 38 


\section{CHAPTER I}

\section{THE PROBLEM AND ITS BACKGROUND}

The middle school transition is often regarded as one of the most challenging periods of a student's educational experience (Akos, 2002). According to Akos (2002), preadolescent students deal with the biological, cognitive, and social changes associated with this developmental period at the same time they experience shifts in school climate and size, peer relationships, and academic expectations. To assist students with this school transition, it is important to understand their range of needs and sources of support. Zeedyk, Gallacher, Henderson, Hope, Husband, and Lindsay (2003) report that transitioning students are most often concerned about bullying, peer relationships, and getting lost. Therefore, it is important for schools to realize that incoming students may be more worried about social issues than academic ones so that they can plan transition programming accordingly. Zeedyk et al. (2003) also found that the skills sought by teachers and understood by them as contributing to a successful transition (e.g., adaptability, confidence) were different from those identified by elementary students (e.g., academic skills). The researchers stress the importance of bridging this gap among student, teacher, and parent perceptions of the school transition so that students feel supported and capable of managing the transition. 
Although the middle school transition is difficult for many students, some Latino students perceive it as especially challenging (Akos \& Galassi, 2004). In addition to the typical issues that arise during the middle school transition and preadolescence, some Latino students deal with linguistic and cultural issues. For example, they may experience stressors due to immigration, acculturation, and language barriers depending on variables such as their length of residency in the United States. Limited English proficiency often impedes students from successfully, and comfortably, interacting with their teachers and peers. This challenge is especially troublesome since teachers and peers are important sources of support for students transitioning to middle school (Akos, 2002).

The purpose of this study was to learn how Latino emergent bilingual students anticipate and experience the transition to middle school. The term emergent bilinguals will be used to describe the participants in this study who spoke Spanish as their native language and who were in the process of becoming bilingual and biliterate in English and Spanish during elementary school (Reyes \& Azuara, 2008). The term English language learner (ELL) is often used to describe such individuals, but it is more accurate for students for whom the result of language learning is not bilingualism, but monolingualism in the second language (e.g., English). The majority of research in this area uses the term English language learner because English fluency is targeted more often than bilingualism in the U.S. Participants in this study were students who attended a bilingual elementary school program (i.e., they were working towards becoming bilingual and biliterate) and had transitioned into their first, second, or third year of junior high school in another building where fluency in English was the primary goal. 
It is important to investigate how emergent bilingual students experience the transition to middle school because they are a growing population that confronts unique challenges (e.g., reductions in language supports and drastically different school environments; Verdugo, 2006). Students in bilingual elementary school programs are generally transitioned into mainstream (i.e., English-only) settings upon entrance into middle school (Baker, 2011). Even if these students receive English as a Second Language (ESL) services in junior high school, the services are most often delivered in a very different context from that which the students were used to in elementary school. For instance, the participants in this study came from an all-bilingual elementary school classroom in which the students were all native Spanish-speakers and the teacher used both English and Spanish during instruction. In middle school, language services are more often delivered in pull-out settings or using ESL instructional techniques that are not specific to the Spanish language (Baker, 2011). Further, based on varying levels of English proficiency, time in the United States, and home environment, students coming from the same bilingual program may have differential pathways of adaptation and integration into middle school. Therefore, it is important to gain an understanding of the range of needs and strengths of emergent bilingual students so that schools and families can help them successfully transition to junior high school. Due to their growing population, Latino emergent bilingual students are one group of immigrant children that deserve further attention.

Due to the rich, descriptive data that can be obtained from qualitative research methods, the researcher held focus group discussions with participants to better understand their anticipations of and experiences with the middle school transition. By 
investigating Latino emergent bilingual students' concerns and systems of support, the results of this study add to our understanding of factors important in the middle school transition for this population of students. 


\section{CHAPTER II}

\section{REVIEW OF RELATED LITERATURE}

According to Akos and Galassi (2004), the transition to middle school may be "a key point in the developmental trajectory of Latino students that can be used to prevent high rates of educational failure and dropping out" (p. 108). Therefore, it is critical that schools understand immigrant and non-immigrant Latino students' unique cultural and educational backgrounds and pay particular attention to them as they make the transition. Akos and Galassi (2004) suggest that students' abilities to capitalize on social support systems are an important component of a successful transition. It is essential that schools provide Latino students with quality transition programming and ensure that they have sufficient access to sources of support.

\section{Demographics}

The participants in this study were native Spanish-speakers who were enrolled in Spanish-English bilingual education. Therefore, demographic information is provided related to the Hispanic population in general as well as the portion of the Hispanic population constituted by English language learners (ELLs).

\section{National Hispanic Demographics}

Hispanics are the second fastest growing ethnic group in the U.S., with an increase of 15.2 million from 2000 to 2010 (Humes, Jones, \& Ramirez, 2011). In 2012, 
about $35.5 \%$ of Hispanics in the U.S. were born in another country (Krogstad \& Lopez, 2014). Among the U.S. population five years of age and older, Spanish was the most common language other than English spoken at home (U.S. Census Bureau, 2012a; 2012b). When discussing the U.S. Hispanic population, it is important to acknowledge the significant diversity that exists within it. According to the Office of Minority Health and Health Equity (2012), Hispanics living in the United States are descendent from people who primarily come from Mexico (63\%), followed by Puerto Rico (9.2\%), Cuba (3.5\%), El Salvador (3.3\%), and the Dominican Republic (2.8\%). Although it is more accurate, and more appropriate, to describe Hispanic individuals using their specific nation of origin (e.g., Mexican, Mexican-American, Puerto Rican, Cuban), the U.S. Census uses the term "Hispanic" to encompass all of these groups. In this study, the term "Latino/a" will be used in addition to "Hispanic" since preferences for one term over the

other vary across individuals. In addition to a student's nation of origin, it is beneficial to consider students' native language literacy skills, levels of English proficiency, and time in the U.S. when investigating how Hispanic students from immigrant families experience school and the school transition (Bartlett \& Koyama, 2012).

\section{Hispanic ELL Demographics}

Thirty-seven percent of fourth grade Hispanic students and $21 \%$ of eighth grade Hispanic students were English language learners in 2009 (Hemphill \& Vanneman, 2011). Although the No Child Left Behind (NCLB) Act of 2001 uses the term 'limited English proficient' to refer to students who are acquiring English for their education, current practice more frequently uses the term 'English language learner' (No Child Left Behind Act, 2002; Verdugo, 2006). To identify students as "English language learners" (ELLs) 
in Illinois, newly enrolled students are administered a Home Language Survey (Chico \& Koch, 2011). If a language other than English is spoken at home, districts assess the student's English language proficiency. Those students whose scores indicate they are not "proficient" in English are identified as English language learners and are eligible for ELL services. The majority of Hispanic students who are first- and second-generation immigrants are English language learners and therefore merit support with the cultural and linguistic changes they experience at school and at home. These changes, as well as generational status (e.g., first-generation immigrant), will be discussed below.

\section{Academic Achievement of Immigrant and Non-immigrant Hispanic Students}

According to Jesse, Davis, and Pokorny (2004), Hispanic students as a whole tend to score lower on measures of academic achievement in both elementary and secondary schools in comparison to their White peers. This phenomenon is referred to as an 'achievement gap.' Although the achievement gap between Hispanic and White students has declined since 1975, changes in the size of the achievement gap on the NAEP during this time have largely been statistically insignificant, especially around the middle school years (Perie, Moran, \& Lutkus, 2005). Given the lower achievement rates of Hispanic students in comparison to their White peers, it is critical that schools across the country determine the most appropriate and effective ways to support Hispanic students, given that they often encounter discrimination and institutionalized barriers that will be discussed below.

The purpose of this study was to examine the experience of Latino emergent bilingual students, so it is also important to examine the academic performance of Latino students from immigrant families for whom English is a second language. Findings from 
the American Community Survey demonstrated that the high school dropout rate for Hispanics born outside of the United States was $31 \%$, compared to the $16 \%$ overall Hispanic dropout rate (Aud et al., 2012). This information suggests that immigrant Latino students experience more difficulty in school than their native-born counterparts. It is important to note, however, that the heterogeneity of the U.S. Hispanic population is not represented in those percentages. Moreover, Nesman (2007) also found that Latino students who were new immigrants and learning English had a higher dropout rate than their U.S.-born peers; however, more acculturated Latino students demonstrated a higher dropout rate than their ELL peers when the data were controlled for socioeconomic level. These disparities between children of different generational statuses will be discussed further in the section related to the immigrant paradox and various groups' differential pathways of adaption to a host culture.

\section{Influences on Immigrant and Non-immigrant Hispanic Student Outcomes}

In order to properly inform future research and intervention planning, schools and researchers must gain a better understanding of the different factors that lead a significant number of immigrant and non-immigrant Latino students to experience psychosocial problems as well as drop out of school, while other Latino students excel academically and socially. The significant dropout rate of Latino students has been attributed to a number of factors, many of which vary with the students' immigrant status. For example, U.S.-born Latino students whose parents were born in the U.S. may struggle in school due to challenges associated with low socioeconomic status, while immigrant Latino students may also experience acculturative stress and feelings of marginalization from their peers due to a lack of English language proficiency (Nesman, 2007). 


\section{Perceived Discrimination}

Both immigrant and non-immigrant Latinos face a number of institutionalized challenges that contribute to perceived discrimination from other ethnic groups (García Coll \& Marks, 2012; Organista, 2007). Immigrant and non-immigrant students' experiences with perceived discrimination can significantly impact their academic and behavioral performances. According to Verdugo (2006), many Hispanic students have reported that their teachers do not understand, or are insensitive to, their cultural, linguistic, and economic backgrounds. Moreover, some students perceive teachers as showing favoritism to White students, and others feel as though their teachers have lower expectations of Hispanic students (Nesman, 2007; Verdugo, 2006). To facilitate positive teacher-student interactions and plan intervention programming for a student population that includes children of immigrants, it is necessary to contextualize students' needs and strengths within their ethnic, linguistic, and cultural backgrounds.

\section{Acculturation}

Acculturation refers to the cultural changes that result when an individual who developed in one cultural context comes into contact with a new cultural context (Berry, 1997). These changes include alterations in customs, economic life, attitudes toward an individual's cultural identity, and social behaviors among different groups. The outcomes of the acculturation process vary in relation to the degree to which individuals maintain their heritage culture and identity and/or engage with the larger mainstream culture (Berry, Phinney, Sam, \& Vedder, 2006). An immigrant's experience with acculturation, and his or her related acculturation strategy, is influenced by a number of group level (or situational) variables (e.g., political context of society of origin; attitudes toward 
multiculturalism of society of settlement) and individual level variables (e.g., age of immigration, education, status, flexibility, coping strategies, social support; Berry, 1997).

The acculturation experience consequently influences a number of variables, including immigrant students' academic achievement. For example, Carranza, You, Chhuon, and Hudley (2009) found direct effects of acculturation on the academic achievement of 298 first- and second-generation Mexican American adolescents. Specifically, students who reported being more acculturated also reported having higher GPAs. Other research has demonstrated that individuals with orientations toward both Mexican and U.S. culture are most likely to achieve school success (Berry et al., 2006). Similarly, Roche, Ghazarian, and Fernandez-Esquer (2012) found that second-generation Mexican immigrant youth who reported greater English proficiency, endorsed the individualistic value of schooling, and more strongly valued familism and same-ethnic friendship networks demonstrated higher educational attainment than their peers. Familism, which is a value dominant in Latino culture, emphasizes family attachment, loyalty, solidarity, and cooperation.

In addition to immigrants' academic functioning, acculturation has been shown to influence their psychosocial functioning. For instance, when individuals have a difficult time adapting their behavioral repertoire to their new cultural context, they often experience acculturative stress (Berry, 1997). This type of stress stems from the conflict between the cultural values and practices of an individual's host and native countries. Language difficulties and perceived discrimination by members of the host society also contribute to acculturative stress (Crockett, Iturbide, Torres Stone, McGinley, Raffaelli, \& Carlo, 2007). First- and second-generation immigrants are most likely to experience 
acculturative stress, but later generations also experience cultural self-consciousness and conflicting value systems. Acculturative stress is also influenced by the motivation behind the immigrant's migration (e.g., proactive/voluntary vs. reactive/forced; Berry, 1997).

According to Lim, Yeh, Liang, Lau, and McCabe (2009), immigrant children are more likely than their immigrant parents to accept and adopt the values and norms of the mainstream culture. When individuals from different generations acculturate to the host country at different rates, an "acculturation gap" is said to exist between those generations. Acculturation gaps have been associated with breakdowns in family communication, the adoption by children of conflicting values, and a sense of distance between parents and their children (Dennis, Basañez, \& Farahmand, 2010). According to Choi, He, and Harachi (2008), acculturation gaps (or discrepancies), which are common in immigrant families, are positively related to intergenerational conflict.

Intergenerational conflict (IC) may be a result of adolescents' changing views of autonomy, family rules, and parental authority, and it often revolves around mundane issues such as chores, clothing style, and curfew (Li, 2014). Intergenerational conflict is more likely to occur in immigrant families than nonimmigrant families, and it may involve generational differences in linguistic habits (e.g., children's poor proficiency in parents' native language and/or use of English at home), preferences for customs of the heritage or mainstream culture, and perceived discrimination from others. According to Lim et al. (2009), parent-child intergenerational conflict is a significant predictor of negative youth outcomes (e.g., low self-esteem, depression) and negative family 
outcomes (e.g., family stress, distrust, isolation). Although intergenerational conflict has been shown to result from acculturation gaps between immigrant parents and children, it is important to acknowledge the protective factors common among immigrant families. Hernandez, Denton, Macartney, and Blanchard (2012) outlined the numerous resources found in many immigrant families, including an increased likelihood of a two-parent home, a strong family work ethic, working mothers who contribute to the family's financial situation, and homeownership. These factors typically contribute to a stable home environment that values education and is supportive of positive child development.

\section{Generational Status}

A topic related to but distinct from acculturation is generational status. Immigrant or generational status refers to whether or not individuals and their parents were born in the host country (e.g., U.S.) or their native country (e.g., Mexico; Bui, 2012). Firstgeneration immigrants include foreign-born students whose parents were also born in their native country. Second-generation immigrants include U.S.-born students with at least one foreign-born parent. The third-plus generation consists of U.S.-born students who have U.S.-born parents. Immigrants who were born abroad but migrated before age 12 constitute are considered 1.5-generation immigrants (Faulkner \& Cardoso, 2010). Children from the 1.5 generation share circumstances with first- and second-generation immigrants since they experience the process of immigration and most often speak a language other than English at home but are primarily educated in U.S. schools. Participants in the current study include 1.5- and second-generation immigrant children.

Studies comparing academic, behavioral, and social outcomes for students of different generational statuses have found what has been termed the 'immigrant paradox.' 
The immigrant paradox is a set of findings indicating that second- and third-generation Latino children in the U.S. perform more poorly academically, behaviorally, and socially than first-generation Latino children (García Coll \& Marks, 2012). As Valenzuela (1999) notes, Mexican students who are more acculturated do not achieve at the same rate as recent Mexican immigrants, even though more acculturated students have a better command of English. Valenzuela (1999) attributes this finding to the tendency of some schools to discount students' native cultural variables, even those that had assisted Mexican students (e.g., ethics of hard work and genuine caring). Throughout the process of acculturation, such native cultural variables are often replaced by behaviors that are more prevalent in the U.S. (e.g., engaging in sexual intercourse as an adolescent, delinquent or illegal behaviors, and the use of controlled substances; García Coll \& Marks, 2012).

This idea that becoming "more American" results in poorer developmental outcomes runs contrary to the traditionally held, even institutionalized, belief that learning English and assimilating are the keys to successful immigration. García Coll and Marks (2012) explained that not all ethnic groups are at risk for all negative developmental outcomes, which makes the paradox an interesting area of research. Han (2012) described the complex interaction between generation status and degree of bilingualism on the outcomes of Latino children. For instance, when Latino children had strong English skills, second-generation students had better academic outcomes than their first- and third-generation peers. When Latino children had lower English proficiency, though, first-generation students demonstrated better academic performance than their second- and third-generation peers. This second scenario exemplifies the immigrant 
paradox. The stronger academic performance exhibited by first-generation students with lower English proficiency may be a result of "protective cultural capital," such as familial respect and a high value placed on education (Han, 2012, p. 180). It is important to consider the multiple factors that influence the academic outcomes of emergent bilingual students, including their generational status, acculturation level, educational experiences, and proficiency in both their native and second languages. Second language acquisition and models of bilingual education are discussed below.

\section{English Language Acquisition}

Although the social and familial stressors related to acculturation can be significant risk factors for Latino emergent bilingual students, research suggests that language itself is another significant obstacle for many Hispanic immigrant individuals as they continue to engage with mainstream American culture (Verdugo, 2006). According to self-report measures, one in five Hispanics living in the U.S. do not speak English or do not speak English well. When working with and evaluating the progress of students who are acquiring another language, it is important to distinguish between two levels of language acquisition: basic interpersonal communication skills (BICS) and cognitive academic language proficiency (CALP; Cummins, 1999).

This distinction between BICS and CALP was highlighted by Cummins (1979), who noted that the two levels comprise conceptually distinct components of the construct of language proficiency. BICS is often referred to as conversational fluency, and CALP is the ability to understand and express academic concepts and ideas (Cummins, 2008). To be successful at school, a student must be able to use academic language, and therefore, demonstrate CALP through both oral and written expression. Cummins (1999) suggests 
that English language learners need to acquire about two years of English exposure to demonstrate peer-appropriate conversational proficiency (i.e., BICS) and approximately five to seven years to approach grade norms (e.g., in vocabulary knowledge) in English. An understanding of the rate of acquisition of these two levels is critical so that reasonable, yet challenging goals can be set and appropriate support can be given to emergent bilingual students. Although a bilingual student may demonstrate strong conversational fluency, it is possible that his or her academic language is less well developed. In these situations, bilingual students are at risk of being exited from bilingual programs or ESL services before they have developed the necessary academic language (Cummins, 1999). Moreover, some bilingual students are mislabeled as learning disabled since their academic skills do not match their conversational fluency and assumed ability. If emergent bilingual students are transitioned into mainstream classes led by a teacher who is unfamiliar with strategies for promoting academic skill in a second language, it is likely that they will continue to achieve below their English-only peers (Cummins, 1999). To ensure that students are fully prepared to enter and succeed in mainstream classes, bilingual programs should address all aspects of language acquisition, including cognitive skills, academic content, and critical language awareness.

\section{Models of Bilingual Education}

There is considerable debate about the extent to which English language learners 'should' maintain their native language as they learn English, especially in the school setting (Slavin, Madden, Calderón, Chamberlain, \& Hennessy, 2011). States and school districts have educated English language learners differently based on their beliefs about second language acquisition. The argument in support of bilingual education emphasizes 
the cognitive benefits of bilingualism and the importance of valuing students' native cultural backgrounds (as discussed below). The argument in support of English-only instruction in schools, on the other hand, posits that bilingual education does not help students become fluent in English as quickly as needed for academic success (Organista, 2007). The purpose of this study was not to compare these models, but to investigate how students from an elementary school that follows a 90:10 developmental bilingual education model (explained below) anticipated and experienced the middle school transition. To accomplish this goal it is necessary to have an understanding of the various models of bilingual education and the emphases they place on English, students' native languages, and their native cultures.

According to Baker (2011), the main goal of bilingual education programs is to help English language learners acquire English to the extent that they will be successful in mainstream education and society. One way to classify bilingual education programs is their language learning outcomes. If the program allows for students to fully develop language and literacy in both the native language (L1) and the second language (L2), the outcome is additive bilingualism and biliteracy. If the program does not permit development of the native language, the outcome is subtractive bilingualism.

Bilingualism has been defined in many ways with different emphases on the level of language control, the range of use, and the different language skills (e.g., listening, speaking, reading, writing; Fitzpatrick, 1987). For the purposes of this study, bilingualism will be defined as the ability to "display any skill (listening, speaking, reading, writing) in functioning in another language other than his mother tongue" (Fitzpatrick, 1987, p. 14). Biliteracy is defined as "any and all instances in which communication occurs in two (or 
more) languages in or around writing" (Hornberger, 1990, p. 213). According to Datta (2000), biliteracy allows people to develop a rich understanding of their languages and cultures and to have greater control over the development of their cultural identity and their academic and career opportunities.

The primary models of bilingual education followed by schools within the U.S. include 1) English immersion, 2) English as a Second Language (ESL), 3) transitional bilingual, 4) maintenance or developmental bilingual, and 5) dual language or two-way immersion (Cardenas-Hagan, Carlson, \& Pollard-Durodola, 2007; Garcia \& Baker, 2007). Three subtractive forms of bilingual education include English immersion programs, mainstream education with ESL programming, and transitional bilingual programs (Baker, 2011). English or 'structured' immersion programs are offered to a class of students who have a primary language (L1) other than English. Instruction is provided almost entirely in English. Initially, teachers may use a simplified form of English and accept some contributions from students in their native language. Later, students are expected to learn and participate entirely in English. English as a Second Language (ESL) programs also occur within a mainstream setting (i.e., in classrooms that serve both English-only students and ELL students and that use English as the language of instruction). This model utilizes strategies that facilitate second language development, especially grammar, vocabulary, and communication. The ESL strategies used in the classroom are often supplemented by ESL programming in a pullout setting.

Transitional bilingual programs are another type of bilingual education model, and they are classified as either early-exit or late-exit (Baker, 2011). Students can be placed in early-exit programs for up to two years. This type of program initially offers 
instruction in the primary language to support early reading instruction and provide clarification for English. The rest of the instruction is in English. Students are then phased out of this program and placed in mainstream English classrooms. In late-exit programs, $40 \%$ of the instructional time is usually conducted in the native language, and $60 \%$ is conducted in English. Students often remain in this type of program until sixth grade or until they meet English proficiency standards (Baker, 2011). Transitional programs tend to be subtractive because they aim to teach English to non-native speakers fairly quickly while phasing out the use of the native language. However, late-exit transitional programs can be somewhat additive if the students strongly develop their L1 during their time in the program.

A fourth model of bilingual education is referred to by many names, such as maintenance, developmental, heritage, and one-way immersion dual language programs (Baker, 2011; Cardenas-Hagan, Carlson, \& Pollard-Durodola, 2007). Students in these programs speak a language other than English, with Spanish as the most common L1. In this model, both language and content are taught in the primary language, and ESL instruction is provided. The goal of this program is to maintain the native language while also developing academic English language proficiency (Garcia \& Baker, 2007). As such, this program is considered additive. These programs generally follow one of two models: 90:10 and 50:50. In the 90:10 model, students begin their education in kindergarten with $90 \%$ of instruction in their native language (e.g., Spanish) and 10\% of instruction in English. Throughout the remainder of their elementary education, students gradually increase the percentage of instruction in English to 50\%. In the 50:50 model, students balance the amount of time they learn and use both languages throughout their schooling. 
Students are most often enrolled in maintenance programs for five to seven years, including kindergarten. The participants in this study were enrolled in a 90:10 developmental bilingual program that ends after fifth grade.

Two-way immersion, or dual language immersion, bilingual education programs consist of approximately equal numbers of English language learners and monolingual English speakers (Cardenas-Hagan et al., 2007). Both native languages, most often Spanish and English, are used for instruction and learning (Baker, 2011). The outcome of dual language programs is additive bilingualism and biliteracy. Adesope, Lavin, Thompson, and Ungerleider (2010) conducted a meta-analysis of research investigating the cognitive outcomes of bilingualism and found that bilingualism is reliably associated with a number of cognitive benefits (e.g., increased attentional control, working memory, metalinguistic awareness, abstract and symbolic representation skills). The two-way immersion model may be implemented by entire schools (e.g., Two Way Schools), but it can also be used in individual classrooms within a mainstream school. This bilingual education model follows one of the two main dual language models (i.e., 90:10 and 50:50) outlined above. Students most often spend up to six years in two-way immersion programs. Participants in this study, though, all attended an elementary school whose bilingual program followed a 90:10 developmental model.

\section{School Transition}

Transitioning to a new school frequently involves changes in school climate and size, peer relationships, and academic expectations (Cauley \& Jovanovich, 2006). School transition (i.e., elementary to middle school, middle to high school) is often regarded as one of students' most difficult educational experiences (Akos, 2002; Zeedyk et al., 2003). 
Although children and adolescents often look forward to new friends, academic subjects, and extracurricular activities, school transition is also associated with considerable stress, worry, and declines in academic performance, school attendance, and self-image (Zeedyk et al., 2003). The feelings of anxiety experienced during the transition are further complicated by hormonal and physical changes associated with puberty, social and emotional development, and the heightened importance of peer relations (Cauley \& Jovanovich, 2006). Researchers have identified that students' greatest concerns about the transition to middle school include bullying, relationships with peers, getting lost, and handling the new workload (Akos, 2002; Zeedyk et al., 2003).

Zeedyk et al. (2003) investigated the perceptions of four groups of school transition stakeholders: primary students in their last year (i.e., eighth grade), secondary (i.e., high school) students in their first year, parents, and teachers. The authors examined similarities and differences among these groups' perceptions of positive aspects of secondary school, student and parent concerns, and ways to ease the transition. Zeedyk et al. (2003) found that primary students who would be transitioning to secondary school believed that the most important skills for a successful transition were academic in nature. In contrast, students who were already in secondary school noted that non-academic skills, such as time management, the ability to focus, good behavior, and social skills were most useful during the transition. This mismatch between children's worries and the skills they will likely need to draw upon suggests a need to prepare and support students for the demands of transition.

Zeedyk et al. (2003) found that student and parent perceptions tended to be similar, but that student and teacher perceptions often differed. When asked about easing 
the school transition, teachers highlighted student confidence as a protective factor, but neither of the two student groups mentioned this student characteristic. Teachers also placed a greater emphasis on the role of the school and its structures than on children's individual abilities and skills. Given that students, parents, and teachers each play a role in students' school transition, Zeedyk et al. (2003) suggested that researchers and practitioners be aware of these different perceptions to create stronger support systems. Finally, even though certain concerns were widely experienced by students (e.g., bullying, peer relationships), Zeedyk et al. (2003) suggested that transition programs should be flexible to address those concerns that are less prevalent but still important to students (e.g., transportation to school, sports ability, forgetting things, any vaccinations needed).

\section{Middle School Transition}

Although many studies of school transition examine the transition from middle school to high school (Zeedyk et al., 2003), it is also important to examine challenges specific to the middle school transition. This transition is unique because students frequently move between environments that are noticeably different (Cauley \& Jovanovich, 2006). For example, in elementary school, most students have one classroom teacher for all core subjects, and some will have had the same classmates since kindergarten. In contrast, middle school students are often in a larger school with multiple teachers, a more complex schedule, and more involved expectations and school policies regarding academics and behavior (Cauley \& Jovanovich, 2006).

Throughout the current study, the transition that the participants made between fifth grade and sixth grade will be referred to as the 'middle school transition' due to the use of this phrasing in the literature, even though the participants in this study were 
students who attended X 'Junior High School.' Differences between 'junior high schools’ and 'middle schools' are often not clearly articulated in research or in practice, though some individuals have a strong preference for one model or the other (Wiles, 2009). Some general guidelines exist to distinguish between the two models that are often based on the school's structure and overall climate. For example, junior high schools often house grades 7-8, though some also house grade 6 or grade 9. Middle schools, on the other hand, most always house grades 6-8.

Regarding the school climate, junior high schools are said to be based on a high school model, whereas middle schools are designed to be more like an extended elementary school. Specifically, junior highs have a more fixed, content-based curriculum and highly structured organization than middle schools, which encourage a curriculum that balances content, skills, and personal development and more flexible organization (Wiles, 2009). Moreover, junior high school teachers are often viewed as subject specialists, whereas middle school teachers, and students, are placed in interdisciplinary teams. According to Wiles (2009), middle schools developed to serve the unique needs of 10- to 14-year-old students who experience a unique transition regarding growth and development.

One criticism of junior high schools is that they focus too heavily on academic development at the expense of affective and social development (Powell, 2004). Although the distinctions between middle schools and junior high schools are often made on paper, the extent to which a school adheres to the model implied by its name varies. Participants in this study attended what were labeled as junior high schools by the school district, but some of their needs seem to have been met using strategies of the middle 
school model (e.g., teams, focus on personal development). It is important to investigate how the Latino emergent bilingual students in this study have experienced the transition to sixth grade in a new building within the context of their individual variables and the environment of their receiving school context.

\section{Academic Outcomes}

Previous research on the middle school transition has demonstrated achievement loss from fifth grade to sixth grade (Alspaugh, 1998) as well as a decline in perceived academic competence, a greater emphasis on relative ability versus individual competency, and declines in year-end grades (Anderman \& Midgley, 1997). Whitley, Lupart, and Beran (2007), on the other hand, found that Canadian students who remained in the same elementary school for seventh and eighth grade did not demonstrate differences in academic achievement from students who transitioned from fifth grade to a junior high school and were therefore expected to demonstrate smaller gains or even losses. These findings were also contrary to what Whitley and colleagues had expected based on their review of previous literature.

\section{Social-Emotional and Behavioral Outcomes}

Because most middle schools integrate students from multiple elementary schools, students often find themselves reestablishing peer groups. Cliques become more prominent, and many students engage in gossip and bullying to maintain their social status (Pelligrini \& Bartini, 2000). In fact, much of the early research on the middle school transition has found negative consequences (Blyth, Simmons, \& Carlton-Ford, 1983; Simmons, Blyth, Van Cleave, \& Bush, 1979). According to Blyth et al. (1983), 
students transitioning to middle school experience decreased self-esteem, reduced participation in school activities, and greater feelings of anonymity.

It is important to consider the developmental stage of students transitioning from elementary to middle school. These students tend to be 10- or 11-years old and are most often considered to be in the early stages of adolescence (American Psychological Association [APA], 2002). This stage of development is associated with many changes in physical appearance, thinking, and social roles. Moreover, adolescents learn to deal with psychosocial changes (e.g., identity development, a sense of autonomy) in different ways (APA, 2002). Self-esteem plays a more central role in students' social-emotional functioning once children enter adolescence. Students also experience cognitive changes in how they think about themselves and others (e.g., parents, peers). Adolescents' perceptions of themselves as students and how they relate to their peers, families, and school staff are important for understanding how these students make the transition to junior high school.

In a yearlong longitudinal investigation, Akos (2002) assessed students' perceptions of school in January and May of their fifth grade year, as well as August and December of their sixth grade year. Akos (2002) utilized a written assignment (e.g., questions students have about middle school) and five- to seven-item questionnaires (e.g., specific concerns, positive aspects, sources of support) to obtain these perceptions. Results indicated that fifth grade students had the most questions about rules, procedures, and expectations, followed by questions about class schedules and physical education class. When asked to report which of 13 concerns they experienced, fifth graders responded fairly evenly across the options. Some of the most frequent concerns were 
older students and bullies, homework, using a locker, and getting good grades. As sixth graders, the participants noted similar concerns, with older students and bullies, getting lost, and doing well in class as the most prevalent. In December, they viewed getting lost, making friends, learning the class schedule, and lockers as the most difficult aspects of school. Interestingly, $14 \%$ of students' responses in August suggested they did not have any concerns, and 5\% of responses in December indicated no difficulties.

To inform how student enthusiasm and areas of confidence can be utilized when planning support systems for transitioning students, Akos (2002) also asked participants which aspects of middle school they viewed as positive. As fifth graders, the students mentioned increased freedom and choices, the opportunity to change classes, and having their own lockers as potential positive aspects of middle school. Similarly, as sixth graders, the students reported that freedom and choices, friends, classes, and lockers were the best aspects of middle school. When asked to whom the students turn for help during the transition to middle school, the most frequent response from the fifth graders was friends (35\%), followed by parents (22\%), teachers (21\%), a school counselor $(14 \%)$, and other sources (e.g., cousins, siblings, and other family; 8\%). As sixth graders, the order and percentages changed slightly, with students still relying primarily on friends $(40 \%)$, teachers $(23 \%)$, and parents $(19 \%)$, with other family $(11 \%)$ and a school counselor $(8 \%)$ as the other sources of support. An aim of the current study was to determine the sources of support utilized by Latino emergent bilingual students in junior high school and investigate how the use of these sources is consistent across students' grade levels and individual variables (e.g., acculturation level). 
According to Cauley and Jovanovich (2006), student concerns about entering middle school fit into one of three categories: academic, procedural, and social. Academic concerns are about schoolwork, teacher expectations, homework, and knowing how to get additional support from teachers when needed. Procedural concerns deal with day-to-day worries about finding classes, being on time, using lockers, and having the appropriate materials for class. Social concerns center around peer and teacher relationships. Cauley and Jovanovich (2006) reported that students worry about making new friends, losing old friends, being in the "right" group, and dating. They also worry about getting along with their teachers and establishing strong relationships like they had with their elementary school teachers. An additional social concern deals with safety issues such as bullying and peer pressure to engage in substance use. The purpose of the current study was to investigate the existence of these types of concerns for Latino emergent bilingual students who have transitioned to junior high school, as well as the participants' ability to cope with and address their concerns.

Considering the numerous developmental changes that students face during the middle school transition, it is critical that schools address students' needs and help them develop coping strategies. Cauley and Jovanovich (2006) note that students generally feel that schools address their procedural concerns; however, they often feel that schools do not pay enough attention to their social concerns. The authors emphasized students' need to perceive their schools as caring, supportive, and invested in their success. This type of environment is especially important for students who are already at risk of struggling socially and academically (e.g., Latino students, students with limited English proficiency) due to factors such as low socioeconomic status, institutionalized barriers, 
perceived discrimination, and conflicts due to cultural and linguistic issues (Jesse, Davis, \& Pokorney, 2004; Organista, 2007; Verdugo, 2006). Ruiz (2009) found that school identification, which includes feelings of belonging and connectedness to the school, teachers, and peers, was the strongest predictor of academic achievement in Latino middle school students. Additionally, in a qualitative study of a bilingual high school for Latino newcomer immigrant youth in New York City, Bartlett and Koyama (2012) found that strong, supportive relationships between and among the teachers, students, and community were among the most important contributing factors to the school's success with serving potentially at-risk immigrant youth.

Further, Garcia, Woodley, Flores, and Chu (2012) argue that Latino students who are acquiring English "need more than to be taught in English only or to simply include their 'native' language and culture" (p. 2). Instead, schools need to create collaborative spaces that transcend linguistic and cultural differences between students' schools and homes. Therefore, it is critical to investigate how Latino students who are learning English experience the middle school transition in order to meet their specific needs.

\section{Latino Students}

The category 'Latino students' is very diverse in terms of students' countries of origin, ethnic self-identification, language(s) spoken, etc. Therefore, consideration of these variables is needed when investigating students' academic and social outcomes using the broad ethnic categories of Latino or Hispanic. Recent research has more closely examined outcomes for specific ethnic groups (e.g., Mexican-Americans, Puerto Ricans, Cubans) and found differential patterns of acculturation and adaptation. For example, Mexican Americans tend to experience greater degrees of conflict and acculturative stress 
than Cuban Americans, which influence how they adapt to mainstream American culture (Organista, 2007).

Unless otherwise stated, the studies outlined below classify one of their participant groups as Latino or Hispanic, without specifying country of origin. For example, Akos and Galassi (2004) used student self-report data from a school transition questionnaire to investigate the psychosocial adjustment (e.g., perceptions of transition difficulty, connectedness to school) of sixth and ninth graders after they made their respective school transitions. Latino students, regardless of their immigration status, perceived the middle school transition as more difficult than their White and African American peers. This greater perceived difficulty by Latino students may be due to a number of factors, including language proficiency for Latino ELLs, peer cultural pressures that conflict with the values and traditions of students' families, and experiences with discrimination.

Additionally, some Latino students, especially if they were not born in the U.S., may experience significant language barriers. As Akos and Galassi (2004) noted, cognitive and linguistic demands are greater in secondary schools than in elementary schools. Students may struggle academically in these more demanding settings, especially if they have difficulty or experience discomfort when interacting with their teachers and peers due to limited English proficiency. Wampler, Munsch, and Adams (2002) found that Hispanic students, primarily of Mexican descent, who transitioned to sixth grade showed a steady drop in their average grade percentages until the last third of the school year, when their grades began to rebound. 
In a longitudinal study conducted with a group of Florida schools, Gordon (2011) investigated whether Hispanic students (both ELL and non-ELL) demonstrated an increase or decrease in their scores on statewide achievement tests after they transitioned from fifth grade to middle school. Based on the previous transition research mentioned above (Alspaugh, 1998; Anderman \& Midgley, 1997), Gordon (2011) hypothesized that participants' achievement test scores would decline from fifth to sixth grade. The results showed, however, that participants demonstrated an increase in both reading and math scores after transitioning to middle school, with a significant increase in reading. It is important to note that participants' increases in scores were not large enough to be considered 'meeting the annual learning gains' for all student subgroups (i.e., ELL status, SES, gender). Large differences in mean achievement scores were found between ELL and non-ELL Hispanic students, with the latter outperforming their ELL peers. This finding suggests that there may be evidence for a significant achievement gap between ELL and non-ELL Hispanic students that merits further attention. It also highlights the importance of contextualizing data within student characteristics such as ethnic background (e.g., Mexican-American, Cuban-American) and language proficiencies to improve the generalizability of findings and inform intervention programming.

Although research on Latino students' experiences with school transition is accumulating, there is much more literature available about Latino students and effective practices in bilingual education in elementary schools (Jesse et al., 2004). Moreover, most of the bilingual education strategies and programs that have been found to be effective are altered or discontinued once students reach middle and high school (Baker, 2011). For instance, the more extensive and additive bilingual education models 
mentioned earlier (e.g., developmental and dual language bilingual education) are typically only offered through fifth grade. By middle school, students are generally expected to have fully transitioned into mainstream (i.e., English-only) education, even though many emergent bilingual students, especially those who immigrate in late childhood and early adolescence, are still developing academic English language proficiency during middle and high school (Cummins, 1999).

\section{ELL Students}

Research shows that to be successful at school, English language learners require more than just the broad-based curriculum that is provided to all students (Gandara \& Rumberger, 2009). They also need additional instructional time to acquire English language and content knowledge, as well as American culture and norms. Furthermore, ELL students would likely benefit from social and emotional support services to address the influences and stressors of immigration and acculturation (Gandara \& Rumberger, 2009). The numerous cultural and linguistic challenges faced by ELL and limited English proficient youth are exacerbated by the additional challenges involved in school transition (Gordon, 2011). Therefore, it is critical that these cultural and linguistic factors, and any reductions in bilingual educational services, are considered by educators and addressed by transition programming.

\section{Transition Supports}

According to Morrison, Robertson, Laurie, and Kelly (2002), social support is an important predictor of school engagement in Latino middle school youth. Specifically, youth who perceived positive social support, participated in classroom activities, and received parent supervision demonstrated more positive levels of school engagement and 
greater involvement in prosocial activities. In contrast, youth who had minimal social supports were more likely to demonstrate problems with their families, peers, and schools. Morrison et al. (2002) suggested that social supports may serve as a safety net for students who are at-risk of feeling overwhelmed by personal and academic difficulties. Given that Latino emergent bilingual students are at-risk of struggling academically and experiencing stressors due to language acquisition and acculturation, it is important that they perceive strong social support. One purpose of this study was to investigate from whom the participants seek support as they transition to middle school.

Efforts to support students through the transition vary by the type and extent of programming offered. In a study by Zeedyk et al. (2003), students, parents, and teachers were asked to provide suggestions for ways schools can help facilitate a smooth transition to high school. Some of the recommendations that have frequently been found in the literature include having high school teachers visit 'primary schools' (i.e., eighth grade students in K-8 schools), having high school students speak to the eighth grade students, and allowing eighth graders to make visits to the high school. There was a strong request for transition programming to take place over several days or weeks instead of just one day of orientation before high school. Further, it was suggested that students in their last year of K-8 elementary schools interact with a high school liaison throughout the year instead of just the last few days.

Other suggestions included the provision of mentoring by high school students, showing videos of high school activities, having counseling readily available for incoming high school students, and greater parent involvement beyond just open evenings held by the school (Zeedyk et al., 2003). Finally, it was suggested that schools 
encourage students to talk about their anxieties. A purpose of the current study was to learn more about students' concerns about the middle school transition. In the process, this study provided participants an opportunity to discuss their concerns and learn about each other's coping strategies during the focus group discussions. Another goal of the study was to determine the types of supports already in place for these students (e.g., by their families, schools, and communities), the effectiveness of the existing supports, and additional supports that may need to be implemented.

Additional research has found transition-programming recommendations similar to those described by Zeedyk et al. (2003) but at the middle school instead of high school level. For instance, Shoffner and Williamson (2000) recommended providing incoming students with their academic schedules early on as well as leading them on tours and establishing a buddy system between incoming sixth graders and older students. Further, George, Breslin, and Evans (2007) suggested having sixth-grade students visit fifth-grade students to talk about their experiences, holding summer academies for struggling students, and leading mini-workshops at the beginning of students' sixth-grade school year to share strategies for easing the transition.

Akos (2002) investigated the support systems of middle school students by giving a questionnaire to 97 sixth-grade students to determine whom they found most helpful during their transition to high school. Forty percent found friends to be the most helpful during the transition, while $23 \%$ chose teachers, $19 \%$ chose parents, $11 \%$ chose other family (e.g., "brothers," "cousins"), and 8\% chose the school counselor. Although these studies are helpful in identifying the various individuals who are looked to for support, additional information is needed that is specific to the middle school transition and that 
clarifies how and when students approach these supports, what they approach them for, and why they are more likely to choose one support system over another.

The current study sought to determine the concerns and support systems of students coming from a Spanish-English bilingual elementary school program as they experienced the middle school transition. Although there is a significant amount of research about the effects of school transition (e.g., increased distress, lower academic achievement), few studies have investigated students' perceptions of their needs during this transition. Even fewer studies have investigated Spanish-speaking emergent bilingual students' experiences with this transition and used qualitative research methods to do so. Akos (2002) suggested that qualitative methods (e.g., interviews with students experiencing the middle school transition) might produce richer information about the positive and negative aspects of transitions than quantitative methods such as questionnaires and analyses of test scores. The purpose of the current study was to begin to fill this gap in the research by using focus groups to determine how Latino emergent bilingual students anticipated and experienced the middle school transition and the resultant changes in bilingual services. Research questions included:

- What was the transition like?

- How did junior high school compare to elementary school?

- What did participants look forward to about junior high school?

- What were participants' sources of concern and support?

- Are there any experiences perceived as unique to Latino emergent bilingual students? 


\section{CHAPTER III \\ RESEARCH DESIGN}

\section{Qualitative Research as Methodology}

The aim of the current study was to explore the Latino emergent bilingual student perspective of the middle school transition and give voice to these students' thoughts, feelings, and experiences. Focus groups were selected as the method of investigation because they encourage participants to share their perceptions and points of view in a relaxed and nonthreatening environment (Krueger \& Casey, 2009). Focus groups allow researchers to better understand how people think or feel about an issue and to develop meaning of the construct under study using the participants' words and experiences. Focus groups also create a comfortable environment in which participants' thoughts and feelings are validated, which is of great benefit to the participants (Krueger \& Casey, 2009). Furthermore, transcriptions of the focus group discussions can be carefully and systematically analyzed to help develop an inductively derived theory about the construct under study (Webster-Stratton \& Spitzer, 1996).

Although quantitative methods such as surveys or questionnaires can be used to investigate the student perspective of the middle school transition, participant responses are limited by the inherent constraints of these methods (e.g., a defined range of responses, scales without room for elaboration; Powell, Single, \& Lloyd, 1996). 
Questionnaires are often designed from the viewpoint of a service provider or researcher; however, information that is valued and therefore assessed by the practitioners and researchers may not align with what matters to the clients or participants. Thus, Powell et al. (1996) suggest that researchers prioritize respondents' hierarchy of importance and use their language, concepts, and frameworks for understanding their environment.

An aim of qualitative research is to explore the reality that participants live as they interact with their changing social contexts (Merriam, 1998). Therefore, instead of focusing solely on the outcomes of the transition to middle school (e.g., academic performance), the current study is designed to examine students' anticipations of and experiences with the transition. Specifically, whereas Gordon (2011) measured Hispanic students' scores on state achievement tests to investigate the impact of the middle school transition on this population, the current study will use focus groups to more fully understand Latino emergent bilingual students' experiences with the middle school transition as it impacts both academic and social functioning.

The products of qualitative research methods such as focus groups are richly descriptive and allow researchers to understand the meaning that people have constructed (Merriam, 1998). Instead of testing existing theory, qualitative research is designed to build concepts, hypotheses, and theories based on the information gathered directly from participants (Merriam, 1998). The purpose of this study was to contribute to the developing understanding of how Latino emergent bilingual students anticipate and experience the middle school transition. The participants' discussions during the focus groups produced a wealth of data about their concerns, copings strategies, and sources of support. 


\section{Participants}

Participants were eight native Spanish-speaking students who completed a bilingual education program at one of two Midwestern elementary schools, which will be referred to as X Elementary School (XES) and Z Elementary School (ZES), and who were enrolled in junior high school at the time of the study. Only one of the participants was enrolled at ZES, and he attended during his fourth- and fifth-grade years. All participants were recruited from a local community center during the beginning of fall semester 2013. Parental permission and child assent were obtained prior to conducting the focus groups. One group was comprised of three sixth-grade students: Daniel, Natalie, and Jesús (see Table 1 on p. 36 for demographic information). The other group consisted of five seventh- and eighth- grade students: Valentina, Mateo, Damien, Alex, and Luis (see Table 2 on p. 37 for demographic information). Participant names have all been changed.

$\mathrm{X}$ Elementary School and Z Elementary School are located in the same metro area. Of the 440 students at XES during the 2012-2013 school year, 39.1\% of XES's student population was White, $34.5 \%$ was Hispanic, 15.2\% was Black, and 9.1\% was multiracial (Illinois Interactive Report Card [IIRC], 2014). Additionally, 32.5\% of the students were classified as English learners. XES had approximately equal numbers of general education and bilingual education classrooms (i.e., two of each classroom in $\mathrm{K}-3^{\text {rd }}$, one bilingual education classroom and two general education classrooms in fourth and fifth grades). The bilingual program at XES follows a 90:10 developmental bilingual model. Therefore, students in kindergarten receive instruction in Spanish for $90 \%$ of the day and 
in English for 10\% of the day. As the students progress through fifth grade, the amount of instruction in Spanish and English gradually reaches parity at 50\% in each language.

Table 1

Summary of Sixth-Grade Focus Group Participants

\begin{tabular}{|c|c|c|c|}
\hline & Daniel* & Natalie & Jesús \\
\hline Gender & Male & Female & Male \\
\hline Grade & $6^{\text {th }}$ & $6^{\text {th }}$ & $6^{\text {th }}$ \\
\hline Age & 11 & 11 & 12 \\
\hline Ethnic Group & Mexican & Mexican & Mexican \\
\hline \multicolumn{4}{|l|}{ Birth country of... } \\
\hline ...participant & Mexico & United States & Mexico \\
\hline ...mother & Mexico & Mexico & Mexico \\
\hline ...father & Guatemala & Mexico & Mexico \\
\hline ...maternal grandparents & Mexico & Mexico & Mexico \\
\hline ...paternal grandparents & Guatemala & Mexico & Mexico \\
\hline Number of siblings & $\begin{array}{l}\text { Three } \\
\text { (3 younger) }\end{array}$ & $\begin{array}{l}\text { Three } \\
\text { (1 older, } 2 \text { younger) }\end{array}$ & $\begin{array}{l}\text { One } \\
\text { (younger) }\end{array}$ \\
\hline \multicolumn{4}{|c|}{ Language(s) spoken with... } \\
\hline ...parents & Spanish, English & Spanish, English & Spanish \\
\hline ...grandparents & Spanish & Spanish, English & Spanish \\
\hline ...siblings & Spanish, English & Spanish, English & Spanish \\
\hline $\begin{array}{l}\text { Language in which } \\
\text { parents watch } T V\end{array}$ & Spanish, English & Spanish & Spanish \\
\hline \multicolumn{4}{|c|}{ On a scale from 1 (not at all) to 5 (almost always), how often would you say... } \\
\hline $\begin{array}{l}\text { "My thinking is done in } \\
\text { the Spanish language. }\end{array}$ & 2 & 4 & 4 \\
\hline $\begin{array}{l}\text { "I enjoy English language } \\
\text { television." }\end{array}$ & 5 & 5 & 4 \\
\hline
\end{tabular}

*All names are pseudonyms.

Z Elementary School (ZES) had 496 students during the 2012-2013 school year and was therefore of a similar size to XES (440 students), but ZES had a different demographic make-up: $46.2 \%$ of students are White, $25.2 \%$ Hispanic, $10.5 \%$ African 
American, and 9.3\% multiracial (IIRC, 2014). The bilingual program at ZES follows the same 90:10 developmental model of bilingual education as XES. However, based on

Table 2

Summary of Seventh- and Eighth-Grade Focus Group Participants

\begin{tabular}{|c|c|c|c|c|c|}
\hline & Valentina* & Mateo & Damien & Alex & Luis \\
\hline Gender & Female & Male & Male & Male & Male \\
\hline Grade & $7^{\text {th }}$ & $7^{\text {th }}$ & $7^{\text {th }}$ & $8^{\text {th }}$ & $8^{\text {th }}$ \\
\hline Age & 12 & 12 & 13 & 13 & 13 \\
\hline Ethnic Group & $\begin{array}{l}\text { Mexican- } \\
\text { American }\end{array}$ & Mexican & $\begin{array}{l}\text { Latin- } \\
\text { American }\end{array}$ & $\begin{array}{l}\text { Latino/a, } \\
\text { Mexican }\end{array}$ & Mexican \\
\hline \multicolumn{6}{|l|}{ Birth country of... } \\
\hline ...participant & United States & $\begin{array}{l}\text { United } \\
\text { States }\end{array}$ & $\begin{array}{l}\text { United } \\
\text { States }\end{array}$ & Mexico & Mexico \\
\hline ...mother & Mexico & Mexico & Mexico & Mexico & Mexico \\
\hline ...father & Guatemala & Mexico & Mexico & Mexico & Mexico \\
\hline $\begin{array}{l}\text {...maternal } \\
\text { grandparents }\end{array}$ & Mexico & Mexico & Mexico & Mexico & Mexico \\
\hline $\begin{array}{l}\text {...paternal } \\
\text { grandparents }\end{array}$ & Guatemala & Mexico & Mexico & Mexico & Mexico \\
\hline Number of siblings & $\begin{array}{l}\text { Two (both } \\
\text { younger) }\end{array}$ & $\begin{array}{l}\text { Two (both } \\
\text { younger) }\end{array}$ & $\begin{array}{l}\text { Three (all } \\
\text { younger) }\end{array}$ & $\begin{array}{l}\text { Two (both } \\
\text { younger) }\end{array}$ & $\begin{array}{l}\text { Two (both } \\
\text { younger) }\end{array}$ \\
\hline \multicolumn{6}{|c|}{ Language(s) spoken with... } \\
\hline ...parents & Spanish & Spanish & Spanish & Spanish & $\begin{array}{l}\text { Spanish (mom); } \\
\text { Spanish, English } \\
\text { (father) }\end{array}$ \\
\hline ...grandparents & Spanish & Spanish & Spanish & Spanish & -- \\
\hline ...siblings & English & $\begin{array}{l}\text { Spanish, } \\
\text { English }\end{array}$ & $\begin{array}{l}\text { Spanish, } \\
\text { English }\end{array}$ & $\begin{array}{l}\text { Spanish, } \\
\text { English }\end{array}$ & Spanish, English \\
\hline $\begin{array}{l}\text { Language in which } \\
\text { parents watch TV }\end{array}$ & Spanish & Spanish & Spanish & Spanish & Spanish \\
\hline \multicolumn{6}{|c|}{ On a scale from 1 (not at all) to 5 (almost always), how often would you say... } \\
\hline $\begin{array}{l}\text { "My thinking is } \\
\text { done in the } \\
\text { Spanish language. }\end{array}$ & 3 & 3 & 4 & 3 & 2 \\
\hline $\begin{array}{l}\text { "I enjoy English } \\
\text { language } \\
\text { television." }\end{array}$ & 4 & 5 & 5 & 5 & 5 \\
\hline
\end{tabular}

*All names are pseudonyms.

Daniel's description and the primary researcher's informal data collection (e.g., observations, conversations with school staff), the two programs seem to implement the 
model a bit differently. The ZES bilingual program may be more true-to-form in that the majority of the emergent bilingual students' fifth-grade year is spent conversing and learning in English. Based on the other participants' descriptions, Spanish may be utilized more often in the fifth-grade bilingual classroom at XES. The implementation of bilingual education models is likely to vary slightly across schools and districts; however, it is important for researchers and practitioners to familiarize themselves with the elementary and junior high school contexts to more fully understand students' development before and after the transition. For example, since Daniel spent more time speaking in English, receiving instruction in English, and working with English-only speaking peers during fifth grade, his adjustment to a sixth-grade classroom in which instruction is entirely in English likely seemed more familiar to Daniel than the other participants who had less exposure to English-only settings.

The junior high school that all but one participant attended after finishing elementary school is X Junior High School (XJHS), which had a total population of 1,203 students during the academic year 2012-2013 (IIRC, 2014). According to the Illinois Report Card (2014), 51.8\% of the XJHS school population was White, 24.9\% was Black, 12.7\% was Hispanic, and 7.8\% was multiracial. Given this demographic information, the emergent bilingual elementary school student participants left an environment in which $34.5 \%$ of their peers were Hispanic and entered an environment in which $12.7 \%$ of their peers were Hispanic. Moreover, their elementary school classroom only contained native Spanish-speaking students. Because there are no bilingual education classrooms at the junior high level, the Latino emergent bilingual students from XES are placed among students from the other feeder elementary schools, the majority of whom are English- 
speaking only. Based on their level of English proficiency when exiting the fifth grade, some Latino emergent bilingual students are placed in classrooms that are instructed by teachers who have been trained in the instruction of English as a second language, along with English-only speaking peers. Other students with stronger English proficiency are placed in general education classrooms. According to the IIRC (2014), only $2.4 \%$ of students at XJHS were classified as English learners.

\section{Setting}

Participants were assigned to one of two focus groups based on their current grade (Group A - sixth graders; Group B - seventh and eighth graders). Seventh- and eighthgrade students were placed in the same focus group because fewer participants were recruited from each grade than was expected. Each focus group lasted about an hour and was conducted by two doctoral students in School Psychology. One student was the primary facilitator of the discussions, and the other student took notes and contributed as desired. The primary facilitator was a White female proficient in Spanish, and the secondary facilitator for both focus groups was a bilingual Latina graduate student. The focus group discussions were held in a large room at a local community center serving a diverse population, including many Latino families. The location was made private, and participants sat in an open, semi-circular formation around a table.

\section{Data Collection}

The two focus groups were conducted in mid-November 2013. The sixth-grade group followed the Focus Group A Session Outline (see Appendix A). The seventh- and eighth-grade group followed the Focus Group B Session Outline (see Appendix B). The primary facilitator explained to the participants that both English and Spanish could be 
used during the focus groups so that the participants felt comfortable and capable of expressing themselves. The sixth-grade participants spoke in Spanish a few times to each other when trying to recall details about people (e.g., "Son cuñadas, right?") and clarify which peer they were discussing:

Natalie: "No es la gordita."

Daniel: “No, yo sé. What's her, what's that girl's name that had the blonde, like that orange hair color?"

Natalie: “Oh, Silvia?” [pseudonym]

Daniel: "Silvia, sí."

The primary facilitator responded to these brief comments in Spanish by smiling when appropriate or responding in Spanish. The majority of the discussion, though, remained in English. All discussion during the seventh and eighth grade focus group was in English.

At the start of each focus group, the facilitators welcomed the participants to the study and introduced themselves. The primary facilitator briefly explained the purpose of the study, and participants were given the opportunity to ask questions. The facilitators obtained written assent before beginning the discussions, and all participants were reminded that they were free to leave the group or refrain from responding at any time, without negative consequences. Each focus group was audiotaped and then transcribed verbatim by the primary facilitator at a later time. Responses in Spanish were infrequent but transcribed directly, and pseudonyms were used for all participants.

The topics of discussion were informed by the research related to the middle school transition and Latino emergent bilingual students outlined above. For example, Cauley and Javonovich (2006) suggested that student concerns related to the middle 
school transition are academic, procedural, or social. Therefore, participants were prompted to discuss any concerns they had in each of these three categories. Additionally, Pelligrini and Bartini (2000) explained that students experience a shift in peer group during the transition, so participants were asked to describe their friendships in elementary school and in junior high school. Finally, because participants were native Spanish-speakers exiting bilingual education, they were prompted to discuss the use of both English and Spanish in class, with peers, and at home. For detailed session outlines for each focus group, see Appendices A and B.

\section{Data Analysis}

The data collected during the focus group discussions were analyzed according to the three-stage data coding process used in grounded theory: 1) open coding, 2) axial coding, and 3) selective coding (Webster-Stratton \& Spitzer, 1996). This method uses a systematic set of procedures to abstract qualitative data into concepts and categories to derive a theory about the constructs under study. The data are constantly compared, contrasted, and linked to build a theoretical explanation using details about how constructs arise, interact, and result in various outcomes (Corbin \& Strauss, 1990). As Merriam (1998) explains, qualitative data analysis is "a complex process that involves moving back and forth between concrete bits of data and abstract concepts, between inductive and deductive reasoning, between description and interpretation" (p. 178). Each stage of the coding process in the current study was conducted by the primary investigator as well as another graduate student to test for intercoder agreement. This process, and its subsequent findings, will be described below in more detail. 
After the focus group discussions were transcribed verbatim by the primary investigator using the audio recordings and co-investigators' notes, the data were subjected to open coding. Specifically, data were broken into small, meaningful units and each discrete "incident, idea, event, or name" was coded as a concept (Webster-Stratton \& Spitzer, 1996, p. 8). In preparation of the second stage of coding (i.e., axial coding), the primary investigator and collaborating graduate student compared these first-level codes and generated ideas about categories. During this stage, any codes that fit an overriding category were grouped together under one axial code. These axial codes are often labeled using the participants' own words or phrases (Webster-Stratton \& Spitzer, 1996). See Appendix C for an outline of the axial codes or 'categories' and their corresponding codes.

The third level of data analysis involved selective coding in which relationships among core categories were investigated and integrated into higher-order categories (Webster-Stratton \& Spitzer, 1996). During this third stage of coding, the primary investigator and collaborating graduate student compared their categories from the second stage and integrated the ways in which these categories could be integrated into themes and patterns of how Latino emergent bilingual students anticipated and experienced the middle school transition.

\section{Dependability}

According to Webster-Stratton and Spitzer (1996), dependability in qualitative research is similar to interrater reliability in that researchers should use other individuals when coding to check for agreement and revise coding schemes as necessary. In the current study, two researchers independently completed the first level of coding (i.e., 
identified and labeled small, meaningful units of data), and then came together to compare their level one codes and reach concordance. When one researcher had a code that the other researcher did not, they discussed the content and quality of the code and decided whether to include, alter, or remove it. After brainstorming possible overriding categories (e.g., likes, dislikes, sources of support) after this initial comparison of first level codes, the researchers then independently completed the second level of coding by fitting the individual codes under emergent categories. Categories that were not consistent across the researchers were identified, discussed, and altered (e.g., combined with another category, deleted) to best fit the codes. While examining the categories, the researchers noted that some categories seemed typical of any middle school transition, whereas others seemed unique to the Latino emergent bilingual participants. These findings will be discussed in the next section. 


\section{CHAPTER IV}

\section{ANALYSIS OF DATA}

This chapter is organized to provide the reader with a brief outline of the focus group discussions (i.e., discussions of elementary school and then junior high school) and a more extensive description of emergent categories. Information shared early in the discussions tended to be concise, but as students became more comfortable with the focus group setting, discussion involved greater elaboration. The units of information identified during the first stage of coding, open coding, most often addressed activities in which the students have been engaged (e.g., playing video games or the flute) or basic information about fifth grade (e.g., teacher's name) that would help participants start to recall their thoughts, feelings, and experiences during that year. The first part of the discussions highlighted participants' experiences in fifth grade and anticipations of the transition to

junior high school. The remainder of the discussions focused on participants' perceptions of the transition and experiences in sixth, seventh, and eighth grades.

Many of the responses provided by participants were similar to those voiced by any middle school student (Cauley \& Jovanovich, 2006). Other topics seemed more salient for the Latino emergent bilingual participants than what has been described in the literature for all transitioning students. This distinction initially became evident during the second level of coding, when the researchers reviewed each unit of information from 
open coding in order to identify emergent categories. For example, the category 'anticipations of junior high school' emerged from the following codes: “didn't know what to expect," "felt a little worried," afraid to "mess up in all those switching hours," excited about "snack bar," and better food. Emergent categories will be presented in an order that creates a coherent narrative of the participants' anticipations of and experiences with the middle school transition.

\section{Participant Background Information}

The sixth-grade focus group was conducted first and included three participants: Daniel, Natalie, and Jesús (see Table 1 on p. 36 for demographic information). Jesús seemed the most hesitant to participate at the beginning of the discussion, but he opened up gradually. Of the three sixth-grade participants, Jesús seemed to be the least fluent in English (i.e., his grammar and syntax were the least complex, he often spoke slowly and with pauses), but he did not speak in Spanish during the discussion. Daniel was the most talkative of the three participants, and he frequently conversed back and forth with Natalie in friendly banter. Natalie had moved to XES in second grade from another state. Daniel stated that Natalie was shy during her initial days in the classroom, and Natalie agreed. Natalie shared a few examples of how she sought guidance and support from different sources, including family and teaching staff. For example, Natalie explained that upon starting at her new school (XES), she thought, “'Oh, I don't know any of these people...' And then my cousin, I, I saw him there, so I'm like, 'Oh. I know one person at least." Throughout the focus group discussion, Natalie was very open to sharing her thoughts and feelings related to different experiences, including those in which she felt uncertain and overwhelmed. Daniel often tried to tell Natalie's story for her because they 
were fairly good friends during second and third grade, and Natalie was comfortable correcting him.

Daniel moved from XES to a nearby bilingual elementary school program (at Z Elementary School [ZES]) in fourth grade after his family moved outside of XES' busing zone. When discussing fourth and fifth grade, Daniel seemed eager to demonstrate greater pride in ZES than XES: "XES...it was lame and I hated the homework...For ZES, the thing I hate is...nothing." Daniel also stated, "[ZES] was much better than XES because in fourth grade, we got to do, we got to do like these, what's it called, um, a house made of, a gingerbread house.” Despite these negative comments toward XES, Daniel made reference to a number of experiences that he greatly enjoyed both at XES and ZES.

The seventh- and eighth-grade focus group included five participants. Valentina, Mateo, and Damien were in seventh grade, and Alex and Luis were in eighth grade (see Table 2 on p. 37 for demographic information). All students knew their grade level peers, and Mateo and Damien appeared to be friends. Damien was extremely quiet throughout the discussion. With the exception of a few responses, each of Damien's contributions to the discussion was in response to a direct question by the primary facilitator. His minimal participation could be related to a number of factors, including shyness around new people or a lower comfort level speaking English. Based on self-report, more of Damien's thinking occurs in the Spanish language than that of his peers. Luis, in contrast, reported spending the least amount of time thinking in the Spanish language. Throughout the discussion, Luis spoke often and provided a number of details. Alex was another active participant, and he seemed to feel comfortable sharing experiences that were 
different than those described by other students. For example, Alex stated that academics in both elementary school and junior high school had been pretty easy for him. Both Luis and Alex tended to contribute the most to each topic of discussion, but Valentina and Mateo also readily shared their experiences. The topics covered in both focus group discussions are presented below. The first section ('Elementary School') describes emergent categories related to participants' elementary school experiences and anticipations of junior high school. The second section ('Junior High School') describes emergent categories related to their experiences upon entering junior high school.

\section{Elementary School}

Participants reflected back to their experiences during elementary school, particularly fifth grade, which was a year and three months prior for Daniel, Natalie, and Jesús, and even longer for the seventh- and eighth-grade participants. Each of the participants, however, was able to provide some details about what he or she had thought and felt prior to making the transition to junior high school.

\section{Program Structure}

As mentioned in Chapter III, XES has an approximately equal number of bilingual education classrooms and general education classrooms. All focus group participants were enrolled in bilingual education classrooms that were comprised solely of native Spanish-speaking students. Participants explained that in Kindergarten through third grade at XES, the large majority of classroom work and conversation was in Spanish. Teaching in fourth and fifth grade also utilized more Spanish than English, but

English began to play a more prominent role in the reading material and language of communication, at least for some students. Jesús reported that time spent learning and 
speaking in English in fifth grade occurred "sometimes, not much." Daniel's fifth-grade experience was different from that of Jesús, his same-grade peer, since Daniel had moved to another school (ZES). As he explained, "Fifth grade...not that much [Spanish]. We only read books in, in English.” Daniel also reported that students were supposed to ask all of their questions in English. At XES, in contrast, Natalie often asked her teacher questions in Spanish.

Eighth-grader Luis perceived fifth grade as "getting more English than Spanish." Additionally, some students from the bilingual classes studied a few subjects (e.g., science) with their English-only speaking peers based on their levels of English proficiency. Alex, who was the only participant to report engaging in this switch, stated, "For me it was kind of different because I got like transferred to some other classes so I could, cause I was kind of advanced in those things.” Even though participants (apart from Daniel) attended the same school for fifth grade, their experiences varied slightly. These differences were due to a number of factors, including the students' proficiency in each language, perceptions of their classroom environments, relationships with their teachers, and/or completion of fifth grade in different academic years.

\section{Connection with School}

Participants' stories and conversations suggested that they were extremely engaged in elementary school, particularly through non-academic activities and strong relationships with teachers.

Memorable activities. Natalie enjoyed participating in a school talent show, taking field trips to the zoo and a nearby university, and participating in the bilingual classes' performance entitled 'Somos Latino'). Daniel recalled special activities that he 
completed such as making a gingerbread house and earning a limo ride from a fundraising project. Daniel also enjoyed participating in the Big Brothers Big Sisters program at both XES and ZES. He shared proudly that his Big Brother at XES had given him "what's it called...He gave me this like, toy car that had like, this remote control" and that his Big Sister at ZES gave him a Spiderman coloring book. Daniel explained, "I still use it. I still like it." The eighth-grade participants shared the sixth-grade students' appreciation for elementary school activities. Alex reported that he liked "everything" about XES, although he specifically enjoyed extracurricular activities such as chess and flag football. Luis added that XES also offered reading club, basketball, and volleyball.

Teacher appreciation. Natalie was excited to report that her fifth-grade teacher created opportunities for students to earn time on the video game system Wii and playing a game that the teacher created. Natalie explained, "Yeah, she let people play Angry Birds, like seriously, like throw them. Like she would bring these Angry Bird things (laughed) and they would like throw them." Jesús, whose responses were often less playful than those of Daniel and Natalie, emphasized that his elementary school teachers were really nice and taught in ways that helped him make sense of the material: "I liked that the teachers were really nice and not like mean and scream at you. And it was fun. And, uh, every time they teach us, it was easy. And sometimes for me, math was kind of hard and I liked how, um, they give you easy ways to teach you, uh, like problems and stuff."

Minor dislikes. Although a majority of the group discussion revealed participants' positive perceptions of their elementary schools, participants also brought up a few dislikes. For example, Alex reported that he did not like the school colors. Luis followed 
up by saying, "the mascot," which elicited a laugh from Alex. Natalie noted that she did not like some of the food, especially the discontinuation of pancakes, but other than that she did not voice any complaints. Daniel, on the other hand, described XES as "lame" and reported that he "hated the homework." As mentioned above, it seemed as though Daniel had developed a strong, almost defensive, affinity for ZES, where he spent his fourth- and fifth-grade years. Apart from the dislikes just mentioned, participants demonstrated very positive attitudes toward their elementary school experiences. None of the participants raised issue with their relationships with peers, teachers, or other staff when asked, nor did they describe significant challenges or sources of frustration, anger, or sadness. Many of the participants smiled and laughed during their recollections of elementary school, which attests to the apparently supportive environment from which they transitioned.

\section{Predominantly Latino Peer Group}

Participants reported having all or almost all Latino friends during elementary school. For example, Jesús estimated that he had "like 10" good friends, each of whom was Latino. Similarly, Luis noted that all of his friends were Latino except one. Daniel reported having the most non-Latino English-speaking friends since many of his fifthgrade experiences occurred in classrooms with English-only speaking peers. Natalie stated that she probably had 10 Latino friends and "then like eight English [friends]" from the time she spent with peers from other classrooms in courses such as physical education and art. 


\section{Excitement and Uncertainty}

All participants mentioned having heard about "the snack bar," and were excited about the better food and greater number of choices in the cafeteria. Natalie, for example, explained how one change she had been looking forward to about junior high was the snack bar. She had imagined it would "be like a little bit better than, um, [XES] because like, um, when my sister was in sixth grade they had slushies." Daniel had a similar impression of the upcoming expansion of the food selections: “There's snack, there's junk food and cookies, and all sorts of soda!" Eighth-grader Alex also mentioned having heard about the snack bar. He noted that on his first day at XJHS, "Everyone was crowding around it. It took a while to open it up."

Although participants were excited about some of the upcoming changes, many of them shared feelings of uncertainty as to what junior high would actually be like day to day. Luis reported having felt a little nervous and stated, 'I didn't know what to expect I guess." Similarly, Jesús had "felt a little worried cuz, um, since in sixth grade you're, um, in middle school and sometimes there are like bullies and that stuff." Natalie explained that she frequently thought about the dress code and how it might be enforced differently in junior high. She also thought that she would "mess up" when trying to switch classes since this process was minimal in elementary school.

\section{Family Support}

While discussing their anticipations of junior high school, participants also described their sources of support. Luis reported learning about junior high school, and later, high school, from his older cousin. Specifically, Luis "heard it was going to be a lot harder" and that he would need to stay on task. Natalie also mentioned learning helpful 
information from a family member: her older sister. Natalie appreciated that her sister looked out for her when they were in elementary school together. For example, following an incident on the bus in which another student hurt Natalie, she was grateful that her sister went with her to the principal's office. Additionally, Natalie had been fairly concerned in fifth grade about the junior high dress code so she asked her sister about how to appropriately wear tank tops. Natalie explained, "Yeah I was thinking about, yeah. And I'm like, you can't wear tank tops without any...I'm like, that's going to be like, you like seriously need to bring like a little jacket or a little sweater."

\section{Transition Programming}

Natalie also inquired about the dress code when the elementary school principal spoke with all fifth-grade students in the gymnasium toward the end of the year. Natalie found this opportunity to ask questions about junior high school helpful. She reported that another student asked for more details about the dress code and whether there would be spirit days in junior high. According to Natalie, "They said that like, the tank tops, like, the really thin ones, yeah, yeah um, you couldn't wear those like without a little like one of those like jackets, uh-huh." Natalie stated that the principal also explained to the students that there would be a school resource officer at the junior high who would be there to help them. Alex reported that this principal was "kind of like a mentor" to him and that he also benefitted from talking with a school counselor.

Jesús mentioned that he was able to visit and take a tour of the junior high school over the summer when he and his mother went to register him for school. Jesús also reported that prior to attending junior high school, he had not heard anything about it until some junior high teachers visited the general and bilingual education fifth grade 
classrooms: "I remember like, about, almost the last year, um, they invited some teachers in junior high to talk about, um, what is going to be in sixth grade, and I learned a lot from that." Jesús stated that he learned a bit about the classes and that lunch would be different and bigger.

\section{Junior High School}

Much of the discussion about junior high school was retrospective in nature, particularly when participants were asked to think back to the first months of sixth grade. Participants also mentioned a few details about their current experiences in sixth, seventh, and/or eighth grade and their thoughts about the near future.

\section{Classroom Structure}

As mentioned in Chapter III, some of the participants' elementary school peers were placed in general education classrooms in sixth grade if they demonstrated a certain level of English proficiency at the end of fifth grade. Natalie, Jesús, Valentina, Mateo, Damien, Alex, and Luis were all placed in sixth-grade classrooms led by teachers with training in the instruction of English as a Second Language (ESL). Daniel had already been in a primarily general education setting in fifth grade at ZES, so his transition to junior high school seemed more similar to that of general education elementary school students. Participants noted that apart from personal conversations, Spanish was almost never used in the classroom, but they did not voice any concerns about this change. Instead, participants stated that they wanted their work to be in English. See below for more information related to language. 


\section{Change and Adaptation}

Participants seemed to have a much easier time identifying differences between elementary school and junior high school than similarities. For example, they noted that junior high starts earlier, is bigger and "faster paced," and has "taller students." Additionally, some participants felt as though their junior high school hallways and buses were more crowded than in elementary school.

Slight adjustments. Alex, an eighth-grade student, noted that although sixth graders switch teachers a few more times throughout the day than they did in elementary school, they largely remain with the same students. He went on to explain, "In sixth grade it was a lot closer to [X Elementary School]. It was a lot more easier than what it is now." Alex's comments suggest that XES and XJHS have created a more gradual transition for incoming sixth grade students and that changes (e.g., in the daily structure) become more noticeable as students progress through seventh and eighth grade.

Welcome changes. Many of the changes that participants noted were perceived as improvements from elementary school. Just as the participants had hoped prior to entering junior high, the food was better, and more options were available. For example, Daniel was quick to point out that compared to XES, the taco shells at ZJHS "[are] better, you know why? Instead of a soft, we get to pick hard, soft, or both.” Additionally, Alex appreciated the transition from a mascot that "sucked" and "made no sense" to one he perceived as "a lot better." Participants also demonstrated an appreciation for the opportunity to take different classes and choose electives. Daniel explained that he liked having a family and consumer science class: "It's fun there. We get to cook, we get to do sewing...Today, we're doing like, we get to, we're painting a wall!" 
Worries. Participants had a lot of positive information to share, but they also disclosed some former worries that spanned academics, social issues, and structural concerns. For example, after starting sixth grade, Jesús became worried about getting poor grades, and Daniel was afraid of first hour "because it was math." Natalie reported feeling worried that there would be conflicts on the bus and afraid of being "squished" by the eighth graders, who seemed very tall. Although the transition to sixth grade was further back in the past for the seventh and eighth grade students, they also disclosed some of their former worries. Mateo, for example, explained that he had felt lost, and Luis, while laughing, agreed: “When I got there, I didn't know where anything was so I just followed everyone."

Resilience. Even though participants experienced uncertainty as fifth graders and various concerns as incoming sixth graders, they described a number of situations in which they addressed these issues and adjusted as time passed. Similar to Mateo and Luis, Jesús also reported that he had difficulty figuring out how to switch classes at first, but he added that he was able to figure it out on his own. Luis had heard that junior high was going to be a lot more difficult than elementary school, "but it was actually easy." Luis reported having some difficulty balancing classes and extracurricular activities at times, but he noted that he greatly enjoys his involvement in activities such as baseball and band.

\section{New Peer Groups and Implications for Friendships}

Due to the convergence of multiple feeder elementary schools and a reduction in the intensity of services offered to bilingual students upon the transition to middle school, participants experienced a shift in the peers with whom they had classes. For Natalie, the transition to junior high school resulted in a significant decrease of the number of 
bilingual females in her classroom. Whereas in elementary school she was always in class with a number of Spanish-speaking Latino peers, only two such peers were in her main classroom in sixth grade, and they were both male students. Natalie reported that two of her female bilingual peers from elementary school were placed in the classroom next to her that also had a teacher with ESL training; however, Natalie does not see these peers very often, and she misses being able to connect with them throughout the day.

Mateo also noted that some of his peers from elementary school were placed in the classrooms with ESL services, whereas others were moved "with just English teachers," or general education classrooms. Similarly, Daniel explained that he only had two bilingual students in his classes and that he primarily saw his bilingual friends from elementary school in the hallways and at lunch. Daniel described his initial days of junior high school, stating, "I was shy. I didn't know anyone because all of my friends were like separated."

Despite these significant changes in classroom peers, participants quickly adapted to their novel peer environment and established new positive relationships. For example, Natalie, who had lamented the lack of Spanish-speaking female peers in her classroom, noted enthusiastically, "My friend told me that it's really awesome that I speak Spanish!" There was a general trend among participants to have almost all Latino friends in elementary school and then at least one half non-Latino friends in middle school. For example, Jesús explained that he had about 10 good friends in elementary school, all of whom were Latino emergent bilingual students. He reported that he only sees a couple of these friends in junior high school. One half of his friends are Latino, and the other half are English-speaking peers of different ethnic backgrounds. Valentina noted that in 
elementary school, all of her friends were Latino emergent bilingual students. Now that she is in junior high school, "probably one or two" of her friends are Latino emergent bilinguals.

\section{Learning and Losing Language}

Participants noted that once they entered sixth grade, teachers spoke only English, and all of their work (i.e., in class and at home) was in English as well. Jesús explained, "At first I thought that English was hard." Alex, on the other hand, stated that he "didn't mind it at all really. It was just a transition." In addition to the use of Spanish and English in their classrooms, participants discussed their use of each language in personal conversations. Each of the participants expressed a concern about losing an important piece of their cultural identity (i.e., their Spanish language). As Valentina explained, "It was actually hard, like losing my Spanish. It was hard to translate it, try to talk with both." Mateo stated that he also notices how he is losing his Spanish, explaining, "I can't remember some words that I used to know." Luis added that he has started to read more slowly in Spanish and have trouble spelling. This discussion revealed that not only was it difficult cognitively for participants to lose their Spanish language, but it was also difficult on a personal level in terms of identity. For example, Jesús noted, "Sometimes at home when I speak Spanish, since I'm speaking a lot of English at school, I'm forgetting like the words." He went on to explain, "I don't want to lose my Spanish 'cause it's my like, my first language."

Participants noted that they still use Spanish in personal conversations, most often in the hallways while talking to friends at their lockers. Daniel and Natalie also reported speaking Spanish when some of their English-speaking peers ask them to translate. 
Natalie reported proudly that her friend, who had told her that it is awesome she speaks Spanish, has also complimented Natalie when she has translated different words and phrases in her classroom. In addition to translating for their peers, many students also reported spending more time at home in a translator role for their Spanish-speaking parents. For example, "the reason I really keep it up, like um, both ways [Spanish and English], is I have to interpret for my parents." Most of the participants identified their parents as important sources of support, which may contribute to participants' dedication to the translator role.

Although participants mentioned concerns about losing their Spanish, they also emphasized their satisfaction with their developing skills and comfort with English. Daniel and Natalie, for example, noted that they understand their English-speaking peers without a problem, and Jesús reported understanding his academics in English just fine. The seventh and eighth grade students each noted that given the choice of having some of their work be in Spanish, they would still want all of their work to be in English.

\section{Family Support}

Participants reported having a number of individuals to whom they felt comfortable turning for information, assistance, and encouragement, including various family members. Jesús reported receiving support from his parents. When participants felt nervous, they reported turning to their aunts, mothers, fathers, cousins, and uncles. When issues related to school arose, Valentina tended to talk to her aunt, and Luis checked in with his older cousin. Daniel explained that if he needed to speak with someone about an issue, especially a social or personal one, he approached his mom. $\mathrm{He}$ noted that he talked to his teachers "only about homework." 


\section{School Support}

Although Daniel seemed to receive primarily academic support from his teachers, other participants expressed feeling comfortable reaching out to their teachers about a number of concerns, including worries about homework and classwork, social issues, and personal issues. Jesús, for example, has discussed worries about his family with his teacher. Jesús also mentioned that he feels comfortable seeking academic help from his teachers, who "really help [him]." Several of the participants noted that their teachers in junior high school encouraged students to seek help during lunchtime or after class. As Luis explained, "It was like the teachers helped you more since you were like getting used to junior high." Teachers had also encouraged participants to gain assistance in this way in fifth grade, so this continuation of support services likely contributed to a smoother transition for participants, as well as greater confidence in their abilities to succeed academically. Although none of the other participants mentioned individual coping strategies, one example of resilient functioning was provided by sixth grader Jesús: "I sometimes talk to myself, that everything is going to be okay and that stuff." Jesús was the same participant who mentioned figuring out his class schedule on his own. Individual coping strategies and self-reliance did not arise as a topic of group discussion in either group, but participants presented as resilient individuals who knew how to rely on themselves and others for support.

Natalie spent a fair amount of time discussing the female Spanish-speaking aide who works in her sixth grade classroom. Natalie explained that she greatly appreciates having someone with whom she can speak Spanish, which she does almost every day. This individual has been particularly important because, as Natalie explained, “There's 
like, only like two [Spanish-speaking] boys that are in my class, like no [Spanishspeaking] girls. Like I like talking to her cuz it's, I'm better talking to the teacher." For Natalie, having a female with whom she can speak in her native language and "have something in common" (e.g., liking takis, which are chips produced by a Mexican company) has been a positive aspect of her transition to junior high school. Natalie's description of her relationship with the bilingual aide suggests that they share more than just a similar snack preference; more importantly, they have formed a cultural connection that is meaningful to Natalie in her new environment.

The bilingual paraprofessional seems to have formed a bridge between Natalie's family supports and school supports. She has created some cultural continuity between Natalie's elementary school experiences in bilingual classrooms and her junior high experience, where most of the individuals speak English and many have different cultural, linguistic, and ethnic backgrounds. This opportunity to form a supportive cultural connection in sixth grade seems to have helped create a smoother transition for Natalie and partly address her desire to connect with others who share her gender, native language, and cultural values.

Overall, participants seemed to benefit from the active efforts by the schools toward transition programming (e.g., opportunities to speak with the elementary school principal and junior high school teachers; placement on sixth grade teams that primarily switch classes together). Participants also took advantage of less formal and less structured support. For example, students' uncertainties during fifth grade were often alleviated through conversations with peers, siblings, and cousins. Additionally, 
participants' worries and concerns as junior high school students were minimized with support from teachers and family members. 


\section{CHAPTER V \\ DISCUSSION}

Results of this qualitative investigation of the middle school transition for Latino emergent bilingual students offer both positive news and an area worthy of further attention. Contrary to what some of the previous research in this area suggested, participants in this small sample enjoyed positive relationships with their peers and teachers; had a number of supports, including family; and did not report struggling academically. Although participants experienced uncertainties about junior high school as fifth graders and faced some challenges as sixth graders, they all reported a largely positive transition. These findings, and the related systems of support described by the participants, may contribute to a framework for transition programming that meets the needs of all students, including Latino emergent bilinguals.

A more serious concern expressed by the students was the partial loss of their native language, which was an important component of their past academic experiences and their culture. Participants expressed a realization that their increasing English proficiency came at the expense of their Spanish fluency because the aim of their education was no longer bilingualism and biliteracy, but fluency in English. This dramatic shift in language use upon the transition to junior high school essentially 
transformed these participants' identities from emergent bilinguals to English language learners.

\section{Interpretations}

Based upon previous research on the middle school transition (Gordon, 2011; Nesman, 2007; Verdugo, 2006), it was anticipated that the Latino emergent bilingual participants would experience concerns about their academic performance and relationships with peers and teachers. Even so, most participants reported satisfaction with their English proficiency, success in their classes, and positive relationships with their Latino and non-Latino peers and teachers. Many factors seem to have contributed to their successes, including support from participants' families and schools as well as individual resilience factors (e.g., flexibility, strong peer relationships, involvement in extracurricular activities, willingness to seek support from a variety of sources). Participants reported concerns typical to any middle school student, regardless of ethnic and linguistic background, such as feeling worried about having to switch classes more often and nervous about bigger students and potential bullying (Akos, 2002; Zeedyk et al., 2003). Participants also reported looking forward to common features of many junior high schools, including better food in the cafeteria and a greater variety of school events and extracurricular activities.

The study's largely positive findings suggest that the participants' elementary schools and junior high schools are already addressing many of the common challenges of the middle school transition and implementing a number of strategies that enhance the support systems of Latino emergent bilingual students (Cauley \& Jovanovich, 2006; Zeedyk et al., 2003). Specifically, participants noted that during their fifth-grade year, 
they benefitted from speaking with elementary school staff (e.g., teachers, principals) and older siblings about what to expect during the transition, having representatives from the junior high schools visit their classrooms, and taking a tour of the junior high schools. Participants' experiences in sixth grade seemed to include different elements that contributed to a continuum of services between the elementary schools and the junior high schools (e.g., very supportive teachers). Teachers have been identified in the literature as an important source of support for students during school transitions (Verdugo, 2006). It became clear from the focus group discussions that all participants' relationships with their teachers, especially sixth grader Natalie's relationship with the bilingual paraprofessional, were central to their positive experiences at each school and during the transition.

As Natalie noted, and as the literature has underscored, friendships and positive peer relations are central to the middle school experience (Akos, 2002). Overall, participants expressed satisfaction with their (new) social relationships. Many students who attend junior high schools that have multiple feeder elementary schools experience a fear of bullying, a shift in their peer groups, and a need to establish new cohorts (Pelligrini \& Bartini, 2000). However, based on Natalie's communication of her transition experience (i.e., feeling the absence of Spanish-speaking female peers in her junior high classroom), this shift in peer group may be experienced uniquely by students leaving all-bilingual classrooms and entering classrooms with peers from varied ethnic, language, and education backgrounds. Natalie explained that she enjoyed having the bilingual paraprofessional in her classroom because they had things in common (e.g., food preferences) and could converse in Spanish. 
Almost all of the participants reported experiencing a loss in their native language as they have become more fluent in English. Maintenance of the native language after students have left bilingual education programming is an area worthy of further attention by parents, educators, and researchers, Additionally, research has shown that bilingualism has cognitive benefits (e.g., enhanced executive control; Bialystok, 2011; Adesope, Lavin, Thompson, \& Ungerleider, 2010), which could help to minimize the achievement gap between White students and Latino students, especially those who are English language learners (Adespoe et al., 2010; Hemphill \& Vanneman, 2011; NCES, 2011). Perhaps more importantly from the student perspective, bilingualism allows students to maintain a strong cultural and linguistic connection to their parents, relatives, Latino emergent bilingual peers, and the Latino communities nearby and in their countries of origin.

The focus group discussions suggested that participants faced a dilemma related to their acculturation experience that became most prominent after the middle school transition. Both 1.5- and second-generation participants struggled to balance their desires to adopt the language of mainstream U.S. culture while maintaining the language of their family and native culture. Although participants in this study were originally in a program that fostered their bilingualism, biliteracy, and biculturalism, they transitioned to an English-only setting that facilitated the loss of their native language. Latino emergent bilingual students, at least in this study, appeared to be emergent bilinguals only during their time in bilingual elementary school programs. Upon the transition to an Englishonly setting in junior high school, participants were supported in becoming fluent English-speakers, but they lost some contact with their native culture. Participants reported feeling glad that they could help their Spanish-speaking parents navigate English 
documents and interactions, but they regretted losing their Spanish vocabulary and fluency.

\section{Limitations and Future Directions}

The aim of this study was to examine the perspective of Latino emergent bilingual students regarding their middle school transition. This student perspective has been largely absent from the literature, even though middle school students are emerging adolescents whose school experiences are largely impacted by their developing selfconcepts and perceptions of their environments. This study's findings contribute to a growing understanding of how Latino emergent bilingual students anticipate and experience the middle school transition, and the elements of transition programming that these students found beneficial.

Although the qualitative methodology utilized in the study produced descriptive information, the small sample size and specific backgrounds of the participants reduce the generalizability of the findings. The primary investigator noticed differences between the two fifth-grade classrooms attended by the participants (e.g., heavier emphasis on English at ZES than XES) that begin to demonstrate the variation in students' fifth-grade experiences, even within the specific target population of Latino emergent bilingual students. All participants were 1.5- or second-generation immigrants, though no noticeable differences were found in their responses. Future researchers may wish to ask participants additional questions about generational status and acculturation to investigate differences related to age of immigration and rate of acculturation. Additionally, each participant had at least one parent born in Mexico, which further contextualizes the participants' responses to primarily Mexican-American students whose families 
immigrated to the Midwestern U.S. Due to the limited generalizability of the findings, it is recommended that future qualitative and quantitative research be conducted with many more participants at the middle school level who have a variety of cultural, linguistic, and educational backgrounds. This type of research would further inform transition programming at different schools to meet all students' needs.

Future researchers might also consider matching the gender of the facilitators to the gender of the participants. Although participants provided information regarding their anticipations of and experiences with the middle school transition, it is possible that male participants would have disclosed even more information in the presence of a bicultural male facilitator with whom they could identify more closely. Additionally, it is possible that participants may have felt more comfortable contributing to the discussion if the primary facilitator had begun by speaking in Spanish, or if the White female graduate student proficient in Spanish was the secondary facilitator and the bilingual Latina graduate student was the primary facilitator. Finally, it is recommended that separate focus groups be held for seventh- and eighth-grade students. Eighth grade participants are more removed from the middle school transition and therefore have different perspectives that could be elucidated further with additional questions specific to their grade level.

One limitation of the current study is that participants' responses were somewhat constrained by the topics pursued by the facilitators as well as participants' comfort level with the group setting. Some participants' responses suggested that they might have had additional details to contribute but felt the need to move on as other participants' responses led the conversation to another relevant topic. The group setting could have led participants to be less forthcoming than they would have been in a one-on-one setting. 
Moreover, it could have led participants to provide socially desirable responses. Future studies should conduct follow-up individual interviews with participants' whose contributions seem representative of the group as well as those that are unique and merit further elaboration. Additional interviews with teachers and parents could also be conducted to supplement the student perspective and determine how often and for what reasons students seek support. It is also recommended that future research employ a longitudinal design in order to examine students' perceptions of the middle school transition at different points in time (e.g., fifth grade, beginning of sixth grade, end of sixth grade).

The focus groups in this study were conducted in mid-November, so it is important to contextualize the discussions within the amount of time that participants had to adjust to middle school (e.g., approximately three months for the sixth-grade participants). It is possible that as time went on, these students would have different experiences that would influence their adjustment, concerns, support systems, and attitudes toward language use. In addition, it is also important to consider the possible influence of selection bias on the study's findings. The students who agreed to participate in the study may not be representative of all local Latino emergent bilingual students. For example, the inferences drawn from the focus groups are based on participants' reports indicating that they were doing well academically and socially. Students who are struggling academically or experiencing familial discord may have be less likely to assent. Moreover, parents who have found the acculturation process to be challenging may also be less likely to give their consent. It is recommended that future researchers conduct focus groups with at-risk adolescents identified by teachers, parents, or community 
members to see if those students have more similar experiences and challenges to those represented in the majority of the literature.

According to Ramirez (2003), Latino immigrant parents may not fully understand the American education system due to linguistic, cultural, and institutionalized barriers, and they may feel as though they do not have control over their children's success at school. These factors influence parents' involvement in their children's education. It is important to note, though, that immigrant parents of both documented and undocumented status highly value their children's learning and should be utilized as an important source of support (Yoshikawa \& Kalil, 2011). The current study found that Latino emergent bilingual students have frequently relied on their parents for social support. Future research should explore the type and amount of communication between parents of Latino emergent bilingual students and their schools, especially in the context of the acculturation experiences and language proficiencies of parents and students. Homeschool collaboration has been found to be a key predictor of student success (National Association of School Psychologists, 2012) and merits further examination with the Latino emergent bilingual population.

While there are numerous opportunities and directions for future research in this area, the findings of the current study can be used to inform future practice. Participants reported benefitting from the transition programming already in place at their elementary schools, including visits from sixth grade teachers and a grade-wide talk with their elementary school principal. Participants appreciated that the principal answered their questions, and he provided useful information about support systems at the junior high such as the school resource officer. Participants also reported feeling comfortable talking 
to their classroom teachers about junior high school, which largely occurred at the end of the school year. It is recommended that fifth-grade teachers check in with their students throughout the year to increase their preparation and comfort level heading into the transition and allow them ample time to ask questions as they arise. As Zeedyk et al. (2003) recommended, students benefit from opportunities to talk about their anxieties to feel supported as they work through them.

Another recommendation for transition programming in the elementary school setting is organizing visits from sixth-grade students in addition to sixth-grade teachers. Two of the participants reported talking to their older siblings or cousins about their concerns or questions; therefore, a visit from sixth graders who have already transitioned could be beneficial, especially for students who do not have older siblings to serve as guides. If possible, the sixth-grade student visitors should include a Latino emergent bilingual student who can speak to the differences in instruction, classroom structures, and peer groups that occur upon entry into sixth grade.

To facilitate a smooth transition once the students begin attending the junior high school, sixth-grade teachers should continue to be welcoming, available sources of support for students as they navigate the changes in environment, instruction, and expectations. Participants emphasized how much they appreciated the help that their teachers offered them (e.g., homework help during lunch and after school) and how they felt comfortable speaking with their teachers about academic, social, and personal issues. Natalie spoke often and highly of the bilingual paraprofessional in her classroom, who seemed to help soften the sharp contrast that often exists in language support and services between bilingual elementary school programs and mainstream or ESL junior high 
classrooms. Although Natalie's experience with the paraprofessional represents one specific teacher-student relationship, it is recommended that sixth-grade classrooms that serve students exiting a bilingual program employ a bilingual paraprofessional when possible. Not all schools will have the resources to do so, but these staff members may be a strong resource for Latino emergent bilingual students.

The continuation of bilingual education into junior high school and high school settings should also receive more consideration from researchers and practitioners to support students' progress toward bilingualism and biliteracy. Finally, because participants reported feeling a loss related to their decreasing Spanish fluency, Latino emergent bilingual students may benefit from an afterschool Spanish club in which they can converse in their native language and possibly teach Spanish to other students.

These recommendations are based on previous literature and the findings extracted from the focus group discussions. When examining and updating transition programming that seeks to meet the needs of a diverse student body, research suggests that it is important to first understand the ethnic, cultural, and linguistic backgrounds of all students, including their respective levels of acculturation, immigrant status, and family circumstances (e.g., parents' language proficiencies). The findings of the current study demonstrate that the middle school transition experiences of Latino emergent bilingual students may involve a unique shift in peer group and a loss of an important piece of their culture (i.e., their native language). Using prior research as a foundation, transition programming should be modified to fit each of the unique needs within a student population. Future research in this area, especially that which considers the Latino emergent bilingual student perspective, will serve as a strong foundation for 
creating a continuum of services between elementary school bilingual programs and junior high schools. 


\section{REFERENCES}

Adespoe, O. O., Lavin, T., Thompson, T., \& Ungerleider, C. (2010). A systematic review and meta-analysis of the cognitive correlates of bilingualism. Review of Educational Research, 80, 207-245.

Akos, P. (2002). Student perceptions of the transition from elementary to middle school. Professional School Counseling, 5, 339-345.

Akos, P., \& Galassi, J. (2004). Gender and race as variables in psychosocial adjustment to middle and high school. The Journal of Educational Research, 98, 102-108.

Alspaugh, J. (1998). Achievement loss associated with the transition to middle school and high school. The Journal of Educational Research, 92, 20-25.

American Psychological Association. (2002). Developing adolescents: A reference for professionals. Washington, D.C.: American Psychological Association.

Anderman, E., \& Midgley, C. (1997). Changes in achievement goal orientations, perceived academic competence and grades across the transition to middle level schools. Contemporary Educational Psychology, 22, 269-298.

Aud, S., Hussar, W., Johnson, S., Kena, G., Roth, E., Manning, E., Wang, X. \& Zhang, J. (2012). The Condition of Education 2012 (NCES 2012-045). Washington, DC: National Center for Education Statistics, U.S. Department of Education. Retrieved March 12, 2013, from http://nces.ed.gov/pubsearch

Baker, C. (2011). Foundations of bilingual education and bilingualism (5 $5^{\text {th }}$ ed.). Clevedon, UK: Multilingual Matters.

Bartlett, L., \& Koyama, J. P. (2012). Additive schooling: A critical small school for Latino immigrant youth. In A. Tyner, \& M. Hantzopoulos (Eds.), Critical small schools: Beyond privatization in New York City urban educational reform (pp. 79-102). Charlotte, NC: Information Age Publishers.

Berry, J. W. (1997). Immigration, acculturation, and adaptation. Applied Psychology: An International Review, 46, 5-68. 
Berry, J. W., Phinney, J. S., Sam, D. L., \& Vedder, P. (2006). Immigrant youth: Acculturation, identity, and adaptation. Applied Psychology: An International Review, 55, 303-332.

Bialystok, E. (2011). Reshaping the mind: The benefits of bilingualism. Canadian Journal of Experimental Psychology, 65, 229-235.

Blyth, D. A., Simmons, R. G., and Carlton-Ford, S. (1983). The adjustment of early adolescents to school transitions. Journal of Early Adolescence, 3, 105-120.

Bui, H. N. (2012). Immigrant generational status and delinquency in adolescence: Segmented assimilation and racial-ethnic differences. In C. García Coll, \& A. K. Marks (Eds.), The immigrant paradox in children and adolescents: Is becoming American a developmental risk? (pp. 135-158). Washington, DC: American Psychological Association.

Cardenas-Hagan, E., Carlson, C.D., \& Pollard-Durodola, S.D. (2007). The crosslinguistic transfer of early literacy skills: The role of initial L1 and L2 skills and language of instruction. Language, Speech, and Hearing Services in Schools, 38, 249-259.

Carranza, F. D., You, S., Chhuon, V., \& Hudley, C. (2009). Mexican American adolescents' academic achievement and aspirations: The role of perceived parental educational involvement, acculturation, and self-esteem. Adolescence, 44, 313-333.

Cauley, K., \& Jovanovich, D. (2006). Developing an effective transition program for students entering middle school or high school. The Clearing House, 80, 15-25.

Chico, G. J., \& Koch, C. A. (2011). Bilingual education programs and English language learners in Illinois: SY 2011 statistical report. Illinois State Board of Education.

Choi, Y., He, M., \& Harachi, T. W. (2008). Intergenerational cultural dissonance, parent-child conflict and bonding, and youth problem behaviors among Vietnamese and Cambodian immigrant families. Journal of Youth and Adolescence, 37, 85-96.

Corbin, J., \& Strauss, A. (1990). Grounded theory research: Procedures, canons, and evaluative criteria. Qualitative Sociology, 13, 3-22.

Crockett, L. J., Iturbide, M. I., Torres Stone, R. A., McGinley, M., Raffaelli, M., \& Carlo, G. (2007). Cultural Diversity and Ethnic Minority Psychology, 13, 347-355. 
Cummins, J. (1979) Cognitive/academic language proficiency, linguistic interdependence, the optimum age question and some other matters. Working Papers on Bilingualism, 19, 121-129.

Cummins, J. (1999). BICS and CALP: Clarifying the distinction. (ERIC Document Reproduction Service No. ED 438 551).

Cummins, J. (2008). BICS and CALP: Empirical and theoretical status of the distinction. In B. Street \& N. H. Hornberger (Eds.), Literacy: Encyclopedia of Language and Education Volume 2 (2 ${ }^{\text {nd }}$ ed., pp. 71-83). New York: Springer.

Datta, M. (2000). Bilingual readers. In M. Datta (Ed.), Bilinguality and Literacy (pp. 5892). London and New York: Continuum.

Dennis, J., Basañez, T., \& Farahmand, A. (2010). Intergenerational conflicts among Latinos in early adulthood. Hispanic Journal of Behavioral Sciences, 32, 118-135.

Faulkner, M., \& Cardoso, J. B. (2010). Mexican-American youth: The impact of generation and gender on outcomes in young adulthood. Journal of Immigrant and Refugee Studies, 8, 301-315.

Fitzpatrick, F. (1987). The open door. Clevedon, Philadelphia: Multilingual Matters.

Gandara, P., \& Rumberger, R. (2009). Immigration, language, and education: How does language policy structure opportunity? Teachers College Record, 3, 750-782.

Garcia, O., \& Baker, C. (2007). Bilingual education: An introductory reader. Clevedon, UK: Multilingual Matters.

Garcia, O., Woodley, H. H., Flores, N., \& Chu, H. (2012). Latino emergent bilingual youth in high schools: Transcaring strategies for academic success. Urban Education, 48, 1-30.

García Coll, C., \& Marks, A. K. (2012). Introduction. In C. García Coll, \& A. K. Marks (Eds.), The immigrant paradox in children and adolescents: Is becoming American a developmental risk? (pp. 3-13). Washington, DC: American Psychological Association.

George, M., Breslin, M., \& Evans, W. (2007). Change is hard: Easing into the middle grades. Principal Leadership, 7, 32-35.

Gordon, K. D. (2011). Middle school transition: How it affects the achievement of Hispanic students relative to ELL status, socioeconomic status, gender, and previous test scores. (Doctoral dissertation). Retrieved from ProQuest Dissertation and Theses. (Accession order No. 3482429). 
Han, W.-J. (2012). Bilingualism and academic achievement: Does generation status make a differences? In C. García Coll, \& A. K. Marks (Eds.), The immigrant paradox in children and adolescents: Is becoming American a developmental risk? (pp. 161184). Washington, DC: American Psychological Association.

Hemphill, F. C., \& Vanneman, A. (2011). Achievement gaps: How Hispanic and White students in public schools perform in Mathematics and Reading on the National Assessment of Educational Progress (NCES 2011-459). Washington, DC:

National Center for Education Statistics, Institute of Education Sciences, U.S. Department of Education.

Hernandez, D. J., Denton, N. A., Macartney, S., \& Blanchard, V. L. (2012). Children in immigrant families: Demography, policy, and evidence for the immigrant paradox. In C. García Coll, \& A. K. Marks (Eds.), The immigrant paradox in children and adolescents: Is becoming American a developmental risk? (pp. 17-36).

Washington, DC: American Psychological Association.

Hornberger, N.H. (1990). Creating successful learning contexts for bilingual literacy. Teachers College Record, 92, 212-229.

Humes, K.R., Jones, N.A., and Ramirez, R.R. (2011). Overview of Race and Hispanic Origin: 2010 (C2010BR-02). Retrieved March 01, 2013, from U.S. Census Bureau website: http://www.census.gov/prod/cen2010/briefs/c2010br-02.pdf

Illinois Interactive Report Card (IIRC). (2014). Illinois school report card. Retrieved May 2, 2014, from http://webprod.isbe.net/ereportcard/publicsite/getSearchCriteria.aspx

Jesse, D., Davis, A., \& Pokorny, N. (2004). High achieving middle schools for Latino students in poverty. Journal of Education for Students Placed at Risk, 9, 23-45.

Krogstad, J. M., \& Lopez, M. H. (2014). Hispanic nativity shift: U.S. births drive population growth as immigration stalls. Retrieved on June 5, 2014, from http://www.pewhispanic.org/2014/04/29/hispanic-nativity-shift/

Krueger, R. A., \& Casey, M. A. (2009). Focus groups: A practical guide for applied research $\left(4^{\text {th }}\right.$ ed.). Thousand Oakes, CA: Sage.

Li, Y. (2014). Intergenerational conflict, attitudinal familism, and depressive symptoms among Asian and Hispanic adolescents in immigrant families: A latent variable interaction analysis. Journal of Social Service Reseach, 40, 80-96.

Lim, S.-L., Yeh, M., Liang, J., Lau, A.S., \& McCabe, K. (2009). Acculturation gap, intergenerational conflict, parenting style, and youth distress in immigrant Chinese American families. Marriage and Family Review, 45, 84-106. 
Merriam, S. B. (1998). Qualitative research and case study applications in education. San Francisco, CA: Jossey-Bass Publishers.

Morrison, G. M., Robertson, L., Laurie, B., \& Kelly, J. (2002). Protective factors related to antisocial behavior trajectories. Journal of Clinical Psychology, 58, 277-290.

National Association of School Psychologists. (2012). School-family partnering to enhance learning: Essential elements and responsibilities [Position Statement]. Bethesda, MD: Author.

National Center for Education Statistics (NCES). (2011). Average reading scale score and standard deviation, by sex, racelethnicity, percentile, and grade: Selected years, 1992 through 2011. Retrieved March 31, 2013, from http://nces.ed.gov/programs/digest/d11/tables/dt11_126.asp

Nesman, T. (2007). A participatory study of school dropout and behavioral health of Latino adolescents. The Journal of Behavioral Health Services \& Research, 34, 414-430.

No Child Left Behind Act of 2001, Pub. L. 107-110, § 301, Stat. 1425 (2002).

Office of Minority Health and Health Equity (OMHHE). (2012). Hispanic or Latino populations. Centers for Disease Control and Prevention. Retrieved March 13, 2013, from http://www.cdc.gov/minorityhealth/populations/REMP/hispanic.html

Organista, K. C. (2007). Solving Latino psychosocial and health problems: Theory, practice, and populations. Hoboken, NJ: Wiley \& Sons, Inc.

Pellegrini, A. D., \& Bartini, M. (2000). A longitudinal study of bullying, victimization, and peer affiliation during the transition from primary school to middle school. American Education Research Journal, 37, 699-725.

Perie, M., Moran, R., \& Lutkus, A. D. (2005). NAEP 2004 trends in academic progress: Three decades of student performance in reading and mathematics. Washington, DC: National Center for Educational Statistics, Institute of Education Sciences, U.S. Department of Education.

Powell, S. D. (2010). Introduction to middle school (2nd ed.). New York: Pearson.

Powell, R. A., Single, H. M, \& Lloyd, K. R. (1996). Focus groups in mental health research: Enhancing the validity of user and provider questionnaires. International Journal of Social Psychiatry, 42, 193-206.

Ramirez, A. Y. F. (2003). Dismay and disappointment: Parental involvement of Latino immigrant parents. The Urban Review, 35, 93-110. 
Reyes, I., \& Azuara, P. (2008). Emergent biliteracy in young Mexican immigrant children. Reading Research Quarterly, 43, 374-398.

Roche, K. M., Ghazarian, S. R., \& Fernandez-Esquer, M. E. (2012). Unpacking acculturation: Cultural orientations and educational attainment among Mexicanorigin youth. Journal of Youth and Adolescence, 41, 920-931.

Ruiz, Y. (2009). Predictors of academic achievement for Latino middle schoolers. Journal of Human Behavior in the Social Environment, 19, 419-433.

Shoffner, M. F., \& Williamson, R. D. (2000). Facilitating student transitions into middle school. Middle School Journal, 31, 47-52.

Simmons, R. G., Blyth, D. A., Van Cleave, E. F., and Bush, D. M. (1979). Entry into early adolescence: The impact of school structure, puberty, and early dating on self-esteem. American Sociological Review, 44, 948-967.

Slavin, R. E., Madden, N., Calderón, M., Chamberlain, A., \& Hennessy, M. (2011). Reading and language outcomes of a multiyear randomized evaluation of transitional bilingual education. Educational Evaluation and Policy Analysis, 33, 47-58.

U.S. Census Bureau. (2012a). Language. Retrieved March 3, 2013, from http://www.census.gov/population/www/cen2000/censusatlas/pdf/8_Language.pd $\underline{f}$

U.S. Census Bureau. (2012b). Language spoken at home by state: 2009. Retrieved February 28, 2013, from http://www.census.gov/compendia/statab/2012/tables/12s0054.pdf

Valenzuela A. (1999). Subtractive schooling: U.S.-Mexican youth and the politics of caring. Albany, NY: State University of New York Press.

Verdugo, R. (2006). A report on the status of Hispanics in education: Overcoming a history of neglect. Washington, DC: National Education Association (NEA).

Wampler, R., Munsch, J., \& Adams, M. (2002). Ethnic differences in grade trajectories during the transition to junior high. Journal of School Psychology, 40, 213-237.

Webster-Stratton, C., \& Spitzer, A. (1996). Parenting a young child with conduct problems: New insights using qualitative methods. In T. H. Ollendick, \& R. J. Prinz (Eds.), Advances in Clinical Child Psychology, Volume 18 (pp. 1-62). New York: Plenum Press. 
Whitley, J., Lupart, J., \& Beran, T. (2007). Differences in achievement between adolescents who remain in a K-8 school and those who transition to junior high school. Canadian Journal of Education, 30, 649-669.

Wiles, J. (2009). Developing successful K-8 schools: A principal's guide. Thousand Oaks, CA: Corwin.

Yoshikawa, H. \& Kalil, A. (2011). The effects of parental undocumented status on the developmental contexts of young children in immigrant families. Child Development Perspectives, 5, 291-297.

Zeedyk, M. S., Gallacher, J., Henderson, M., Hope, G., Husband, B., \& Lindsay, K. (2003). Negotiating the transition from primary to secondary school: Perceptions of pupils, parents, and teachers. School Psychology International, 24, 67-79. 
APPENDIX A

FOCUS GROUP A SESSION OUTLINE 


\section{Introduction}

1. Secure child assent using Child Assent Form

2. Give introduction:

"Does anyone have a problem if I turn on the recorder now?" (Turn recorder on and place in center of group.)

"Thank you for joining us. Let me tell you a little more about what we will be doing today. For the next hour and a half or so, we are going to talk about your feelings about going to sixth grade and moving to junior high school. I am going to ask a question and then each one of you will have a chance to speak. Remember, there are no wrong answers so I encourage everyone to speak because I am very interested in what each of you has to say, even if it is different from what someone else says. The more we talk in our group, the more we will learn. But, if you do not have anything to say, that's fine, too."

"I will be asking you about your transition to sixth grade and junior high school. I will ask things that will help me learn about what you have enjoyed so far about being in junior high as well as what has been difficult for you. Then, I would like to ask you how you handle being happy, excited, or worried, and who you turn to if you have questions or want help. Again, everyone will get a chance to speak. Halfway through our group we will have some snacks and take a little break. Do you have any questions about what I just said?"

"Remember, this group is voluntary. That means if you no longer want to be here for whatever reason, let me know and it will be okay for you to leave. Even though I think we will have a good time talking together, it is perfectly okay not to talk or leave."

"Even though you may all know each other, we should try to avoid using each other's real names since we are recording this with your permission."

"What questions do you have? Are you ready to begin?"

Focus Group Discussion Questions (information in italics is to guide the facilitator)

1. ICEBREAKER. - Question Catch.

a. Facilitator begins by holding a soft ball and explains that whoever is holding the ball asks a question (e.g., What is your favorite TV show?) and

b. throws it to a person who will answer the question. The point of the game is to get to know each other and have some fun.

c. The purpose of this icebreaker is to establish rapport with the participants before seeking information.

2. BASIC INFORMATION: Okay. Just so we can get to know each other a bit more, I would like each of you to fill out this form (see Demographic Questionnaire) that asks a few questions about you and your family. When everyone is done, we can share our responses with each other. 
3. FIFTH GRADE: Okay, thank you for sharing. Now let's talk about your elementary school and last year in fifth grade.

a. Tell me about your school.

i. What kinds of things did you like about it?

ii. What kinds of things did you not like about your school?

b. Tell me about your bilingual fifth grade classroom.

i. What kinds of things did you like about it?

ii. What kinds of things did you not like about your classroom?

c. What did you do if you had a problem or were worried about something?

i. Who did you talk to?

d. When you were in fifth grade, what had you heard about junior high?

i. Who did you hear it from?

ii. Did you talk about junior high in your fifth grade classroom?

iii. How did you feel when you were talking about sixth grade?

e. How many good friends did you have in elementary school?

f. How many of your good friends were Latino?

4. SIXTH GRADE/JUNIOR HIGH: Okay, now we are going to talk about your thoughts and feelings about your 'transition' to junior high school, or your move from elementary school to junior high for sixth grade.

a. Tell us about your sixth grade schedule.

i. Classes

1. Which classes did you like the most? Why?

2. Which classes did you like the least? Why?

5. CONCERNS and POSITIVE ASPECTS:

a. Academic

i. Are you concerned about schoolwork in junior high?

1. What kind of concerns do you have?

a. Classes

b. Teacher expectations

c. Homework

d. Getting help

e. Influence of language

ii. What kinds of things do you enjoy about the schoolwork?

b. Procedural

i. Are you concerned about any smaller, everyday things? (e.g., following the rules and being where you are supposed to be on time)

1. Changing classes

2. Supplies

3. Lockers

4. Anything else mentioned in what they have heard about junior high.

ii. Are there any smaller things about junior high that you like? 
c. Social

i. What concerns do you have about the social part of junior high?

Things like being able to see your old friends, making new friends...

1. Friends
a. New
b. Old
2. Dating
c. Influence of language
3. Bullying
4. Peer pressure
5. Teachers
a. Number of teachers
b. Influence of language
ii. What kinds of things do you enjoy about the social part of junior high?
d. Other
$i$. What other kinds of things do you worry about or not like?
ii. What other things do you enjoy?
$e$. How many good friends do you have now?
$f$. How many of your good friends are Latino?

\section{SUPPORT SYSTEMS}

a. What do you do if you're worried about something?

b. If you are worried about school (e.g., academics, procedural, teacher interactions), whom do you go to for support/help?

i. Examples: Parents, other family, friends, teachers

c. If you are worried about something with your family, whom do you go to for support/help?

i. Examples: Parents, other family, friends, teachers

d. If you are worried about your friends, whom do you go to for support/help?

i. Examples: Parents, other family, friends, teachers

e. If you are excited about something, whom do you talk to?

7. Is there anything else you would like to talk about related to moving to junior high? 
APPENDIX B

FOCUS GROUP B SESSION OUTLINE 


\section{Introduction}

1. Secure child assent using Child Assent Form

2. Give introduction:

"Does anyone have a problem if I turn on the recorder now?" (Turn recorder on and place in center of group.)

"Thanks again for joining us. Let me tell you a little more about what we will be doing today. For the next hour and a half, or so, we are going to talk about how sixth grade went for you last year (before) and how seventh (eighth) grade is going. I am going to ask a question, and then each one of you will have a chance to speak. Remember, there are no wrong answers so I encourage everyone to speak because I am very interested in what each of you has to say, even if it is different from what someone else says. The more we talk in our group, the more we will learn. But, if you do not have anything to say that is fine, too."

"The questions I will be asking will be about how your transition from elementary school to junior high school has been. I will ask things that will help me learn about what you have enjoyed so far about the transition to junior high as well as what has been difficult for you. Again, everyone will get a chance to speak. Halfway through our group we will have some snacks and take a little break. Do you have any questions about what I just said?"

"Remember, this group is voluntary. That means if you no longer want to be here for whatever reason, let me know and it will be okay for you to leave. Even though I think we will have a good time talking together, it is perfectly okay not to talk or leave."

"What questions do you have? Are you ready to begin?"

\section{Focus Group Discussion Questions}

1. ICEBREAKER. - Question Catch.

a. Facilitator begins by holding a soft ball and explains that whoever is holding the ball asks a question (e.g., What is your favorite TV show?) and throws it to a person who will answer the question. The point of the game is to get to know each other and have some fun. The purpose of this icebreaker is to establish rapport with the participants before seeking information.

2. BASIC INFORMATION: Okay. Just so we can get to know each other a bit more, I would like each of you to fill out this form (see Demographic Questionnaire) that asks a few questions about you and your family. When everyone is done, we can share our responses with each other.

3. Okay, thank you for sharing. Now we are going to talk about your thoughts and feelings about the 'transition' you made to junior high school, or when you moved from elementary school to junior high. 
4. FIFTH GRADE: First we are going to talk about elementary school and your bilingual fifth grade classroom. I know it has been over a year since you were in fifth grade, so I'd like everyone to think back a bit.

a. Who was your classroom teacher?

b. What did your classroom look like?

c. What were some of your other teachers' names?

d. What are some memories you have from fifth grade?

5. Thank you very much for sharing. Now I want us to talk some more about fifth grade.

a. Tell me about your elementary school.

b. Tell me about your bilingual fifth grade classroom.

c. How many good friends did you have in fifth grade?

d. How many of your good friends were Latino?

e. What did you know about junior high before you started?

f. Who did you learn this from?

g. What kinds of things were you worried about before coming to junior high?

i. Academic

ii. Procedural

iii. Social

iv. Other

h. How did you handle your worries?

i. Who did you talk to?

i. What kinds of things were you excited about?

i. Who did you talk to?

6. JUNIOR HIGH: Okay, now we are going to talk about junior high school.

a. How is junior high similar to elementary school?

b. How is junior high different from elementary school?

c. The next questions are going to focus on last year (or two years ago), when you were in sixth grade. Tell us about your schedule from last year (e.g., classes, teachers).

i. Classes

1. Which classes did you like the most? Why?

2. Which classes did you like the least? Why?

ii. Teachers

d. Academic

i. What concerns did you have last year (or two years ago) about schoolwork in sixth grade?

1. Classes

2. Teacher expectations

3. Homework

4. Getting help

5. Influence of language

ii. What kinds of things did you like about the schoolwork in junior high? 
e. Procedural

i. Were you concerned about any smaller, everyday things? (e.g., following the rules and being where you are supposed to be on time)

1. Changing classes

2. Supplies

3. Lockers

4. Anything else mentioned in what they have heard about junior high.

f. Social

ii. Were there any smaller things that you liked in sixth grade?

i. What concerns did you have about the social part of junior high? Things like being able to see your old friends, making new friends...

1. Friends
a. New
b. Old
c. Influence of language

2. Dating

3. Bullying

4. Peer pressure

5. Teachers

a. Number of teachers

b. Influence of language

ii. What kinds of things did you enjoy about the social part of junior high?

g. Other

$i$. What other kinds of things did you worry about or not like?

ii. What other kinds of things did you enjoy?

h. How many good friends do you have now?

How many of your good friends are Latino?

\section{SUPPORT SYSTEMS}

a. What do you do if you're worried about something?

b. If you were worried about school (e.g., academics, procedural, teacher interactions), whom did you go to for support/help?

i. Examples: Parents, other family, friends, teachers

c. If you were worried about something with your family, whom did you go to for support/help?

i. Examples: Parents, other family, friends, teachers

d. If you were worried about your friends, whom did you go to for support/help?

i. Examples: Parents, other family, friends, teachers

e. If you were excited about something, whom did you talk to? 
8. LOOKING FORWARD TO THIS YEAR: What concerns do you have about this year in seventh (eighth) grade?

i. Academic

ii. Procedural

iii. Social

iv. Family

v. Other (e.g., influence of language)

b. How do you handle them?

i. Who do you talk to?

c. What kinds of things do you enjoy this year about being in seventh (eighth) grade?

d. What kinds of things are you looking forward to about the rest of this year in seventh (eighth) grade?

9. Is there anything else you would like to talk about related to moving to junior high? 


\section{APPENDIX C \\ CODES AND CORRESPONDING CATEGORIES IDENTIFIED DURING \\ OPEN CODING AND AXIAL CODING}


CATEGORIES AND CODES RELATED TO ELEMENTARY SCHOOL

\section{Program structure}

asked questions in English (ZES)

asked questions in Spanish and English

fifth grade getting to be more English than Spanish

more Spanish than English in fourth grade

mostly Spanish in 1st - 3rd

only read books in English (ZES)

priority was Spanish, a little bit of English in fifth grade

\section{Memorable activities}

Big Brothers Big Sisters

bilingual class' performance "Somos Latinos"

field trip to college

field trip to zoo

flag football

fundraiser to ride in limo

making gingerbread house and men

plays flute

reading and chess clubs

talent show

teacher brought iPad

volleyball, basketball

\section{Teacher appreciation}

made work seem easy

only yelled at students who were misbehaving

teacher was fun

teachers were really nice

teachers would help students during lunch

the teachers were nice

\section{Minor dislikes}

boring

hated the homework

it was lame

mascot

school colors

some of the food

Predominantly Latino peer group

all of them Latino

all of them Latino except for one

almost all friends Latino 
English friends from switching classes

like ten good Latino friends

most friends Latino

ten Latino, eight English

\section{Excitement and uncertainty}

a little nervous

all sorts of soda

bus will be more crowded

didn't know what to expect

excited about snack bar

felt a little worried

junk food and cookies

might mess up with switching classes

slushies

thinking a lot about the dress code

worried about bullies

\section{Family support}

cousin said to stay on task

cousin warned it would be harder

mom

mom

older cousin

older sister

siblings

sister explained dress code

\section{Transition programming}

asked about dress code

asked about spirit days

fifth graders from ZES toured ZJHS

learned about school resource officer

principal held discussion

principal spoke to whole 5 th grade about $\mathrm{JH}$

Spanish-speaking students toured YJHS

teachers from junior high visited

took a tour during summer

visited $\mathrm{JH}$ over summer 
CATEGORIES AND CODES RELATED TO JUNIOR HIGH SCHOOL

\section{Classroom structure}

some bilingual students in all English classes

some bilingual students in ELL class with Spanish-speaking teacher

Spanish almost never used

\section{Slight adjustments}

bus is crowded

crowded hallways

faster paced

figuring out changing classes

forgetting homework

gets on bus earlier

have to think harder

have to walk around after every period

junior high is bigger

junior high starts earlier

less time to do work

more work

sixth grade more similar to elementary school than eighth grade

switch teachers a few more times

taller students

\section{Welcome changes}

can choose electives

can get hard and/or soft taco shells

can have cell phones with you

check in about good and bad things about weekend during roundtable cross-country different classes

food was better

have roundtable in the morning

liked family and consumer science class

mascot was a lot better

more food options

track

\section{Worries}

afraid of being squished by eighth graders

bullying

conflicts on the bus

dress code

felt lost

getting an $\mathrm{F}$ or a $\mathrm{D}$, or $\mathrm{C}$

grades 
losing Spanish

not passing sixth grade

passing all classes

pushing in hallways

saw a fight

scared of math at beginning of year

sees bullying sometimes

switching and finding classes

\section{Resilience}

adjusted to waking up earlier

figured out how to switch classes

not worried about friends

overcame difficulty of balancing class and outside activities

taught himself to open locker

uses self-talk when worried about something at home

\section{New peer groups and implications for friendships}

asked by peer to be friends

didn't know anyone because friends were separated

fewer friends in classes

half Latino friends

made friend in class

more than ten friends, five Latino

no bilingual female peers in class

now has 13 English friends

one or two Latino friends

only a couple of the same friends

only sees bilingual friends at lunch and in hallways

sees more friends in the hallway when at locker

shy because friends separated

some English, some Spanish friends

\section{Learning and losing language}

always speak in English in class

can read and write in English fine

can't remember words used to know

didn't really mind going to almost all English

don't really speak Spanish during school

don't want to lose Spanish

easy enough to switch languages with different friends

English peers ask for Spanish help

forgetting the words at home

friend asks her to translate to Spanish

hard to translate and try to talk with both 
it was hard losing Spanish

losing Spanish

mainly speaks Spanish only when translating

now reads slower in Spanish and English

pretty much all of the work is in English

rarely read in Spanish

Spanish is his first language

speaking a lot of English at school

teachers only speak English

translating for parents

translator role with parents

understand academics fine in English

understand English peers fine

use Spanish in personal conversations, not for class

uses Spanish at home, usually when translating

want work to be in English

\section{Family support}

aunt

cousin in high school

dad

mom

support from mom

talked to uncle

\section{School support}

asks Spanish-speaking teacher for help with Reading and English

can get help after class

can get help during lunch

can talk to teacher if worried

comfortable talking to teacher about homework

comfortable talking to teacher if worried about anything

comfortable talking to teachers for help

counselor

discusses worries about family with teacher

gets help during lunch from teacher

Spanish-speaking teacher

talk to teacher

talk to teacher about homework

teacher

teachers helped you more because getting used to junior high

teachers really help

told teacher in Spanish about a movie she watched 